NIST Technical Note 1869

\title{
Research and Development Opportunities for the NIST Net Zero Energy Residential Test Facility
}

Paul D. Domich Betsy Pettit

A. Hunter Fanney William M. Healy

This publication is available free of charge from: http://dx.doi.org/10.6028/NIST.TN.1869
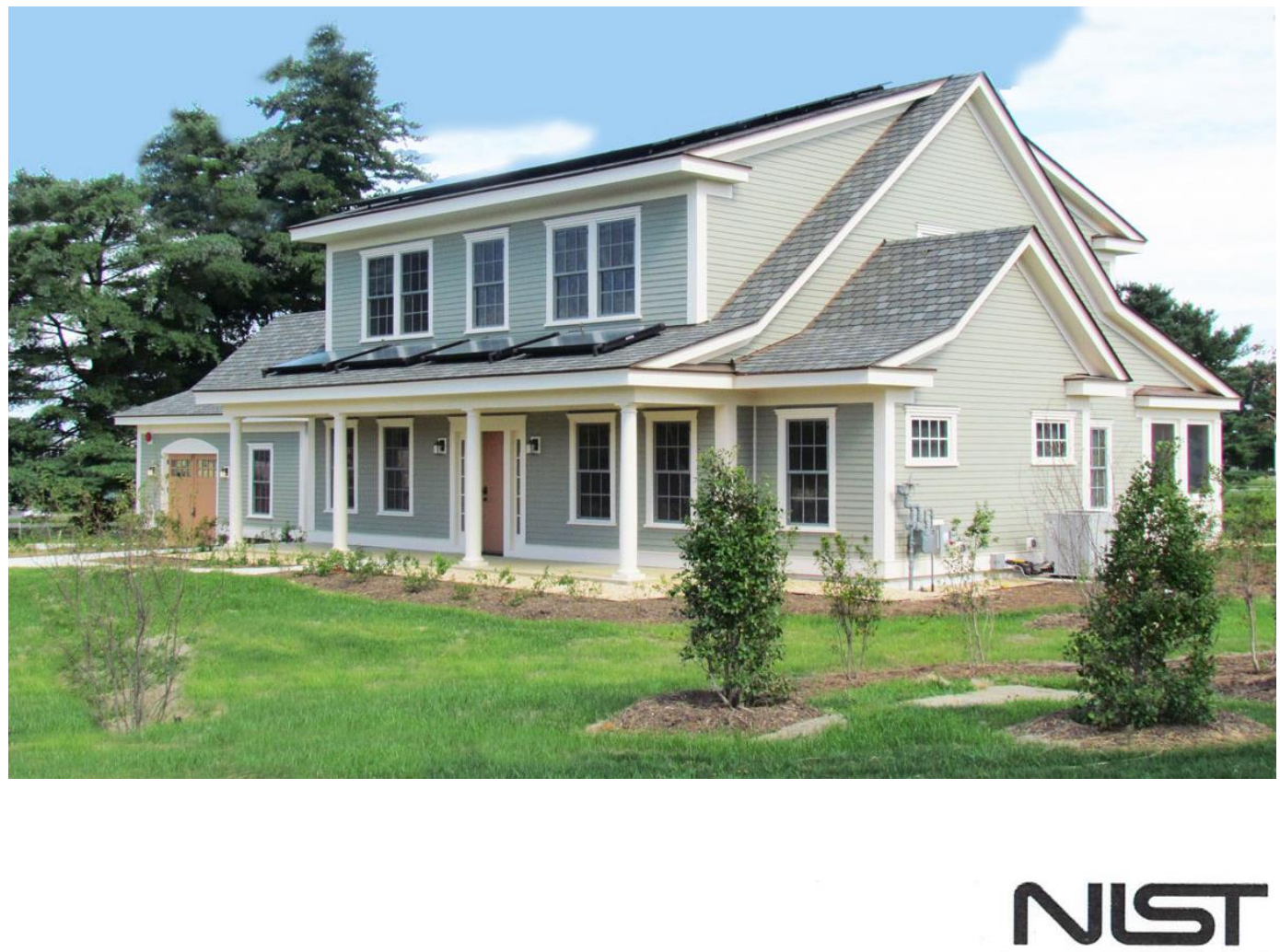

National Institute of Standards and Technology

U.S. Department of Commerce 


\title{
Research and Development Opportunities for the NIST Net Zero Energy Residential Test Facility
}

\author{
A. Hunter Fanney \\ William M. Healy \\ Energy and Environment Division \\ Engineering Laboratory \\ Paul D. Domich \\ CIP Consulting, Inc. \\ Boulder, $\mathrm{CO}$ \\ Betsy Pettit \\ Building Science Corporation \\ Somerville, $M A$
}

This publication is available free of charge from http://dx.doi.org/10.6028/NIST.TN.1869

March 2015

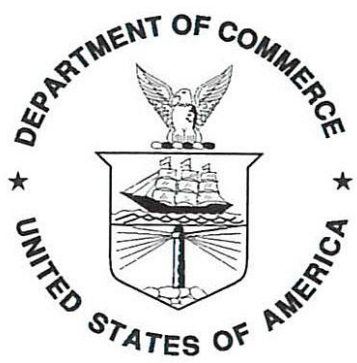

U.S. Department of Commerce Penny Pritzker, Secretary

National Institute of Standards and Technology Willie E. May, Under Secretary of Commerce for Standards and Technology and Director 
Certain commercial entities, equipment, or materials may be identified in this document in order to describe an experimental procedure or concept adequately. Such identification is not intended to imply recommendation or endorsement by the National Institute of Standards and Technology, nor is it intended to imply that the entities, materials, or equipment are necessarily the best available for the purpose.

National Institute of Standards and Technology Technical Note 1869

Natl. Inst. Stand. Technol. Tech. Note 1869, 64 pages (March 2015)

This publication is available free of charge from

http://dx.doi.org/10.6028/NIST.TN.1869

CODEN: NTNOEF 


\begin{abstract}
The National Institute of Standards and Technology (NIST), through American Recovery and Reinvestment Act of 2009 (ARRA) funding, built the Net-Zero Energy Residential Test Facility (NZERTF) as a NIST laboratory in the form of a typical residence to measure performance and document new building technologies and designs for achieving net-zero energy consumption. The style and size of the house is typical of a residence that might be built in the local suburban area for a family of four, offer the modern amenities typically found in single-family housing, and meet the needs of a typical family of four while achieving net-zero site energy use on an annual basis. The laboratory's measurement and testing systems operate independently of the residential systems. Net-zero energy use was accomplished through the combination of low space-conditioning loads due to a high-performance envelope, efficient heating, cooling, and ventilation systems, low-energy lighting fixtures and appliances, and site-generated renewable energy using solar photovoltaic and thermal systems. The facility is capable of using and evaluating performance of typical earth-source geothermal heating systems.

This paper describes future research and development topics that can be performed in the NZERTF. Through focused interviews, research topics were solicited from twenty-two organizations familiar with net-zero energy buildings. Research topic areas contained in this report include: envelope design, window systems and glazings, site considerations, heating, ventilation, and air conditioning (HVAC) systems, renewable energy technologies, control systems, and in situ performance testing and building commissioning.
\end{abstract}

\title{
Keywords
}

Research and development, Net-zero energy residential design, high performance enclosures and building components, energy efficiency, water reuse and conservation. 


\section{Contents}

Abstract

Keywords

List of Acronyms $\quad$ v

List of Figures $\quad$ viii

List of Tables $\quad$ ix

1 Introduction $\quad 1$

1.1 Background and Purpose 1

1.2 Overview of the Investigative Process

1.3 Definitions: What is a net-zero energy house?

2 NZERTF General Information $\quad 3$

2.1 Climate, Site, Form, and Orientation 3

2.2 Renewable Net-Zero Energy Requirements 4

3 Major Building Components in the Net-Zero Energy House 5

3.1 Building Enclosure/Envelope $\quad 6$

3.1.1 Building Enclosure Design $\quad 6$

3.1.2 Enclosure Airtightness $\quad 8$

3.1.3 Location, Type and Size of Windows 9

3.1.4 Conditioned Attic and Basement 11

3.1.5 Foundation Wall 11

3.2 Space Conditioning Systems

3.2.1 Central Air Split System - Dedicated Dehumidifying Two-Speed Heat Pump 13

3.2.2 Air Source Heat Pump System 14

3.2.3 Central Air Distribution Systems 16

3.2.4 Support for Alternate Conditioning Systems 17

3.2.5 Heat Recovery Ventilator System 18

3.2.6 Other Ventilation Systems $\quad 21$

3.2.7 Geothermal Heating Systems 22

3.2.8 Hydronic Radiant Floor Heating System 24

3.3 Hot Water Systems 24

3.3.1 Solar Hot Water Heating Systems 24

3.3.2 Auxiliary Heat Pump Water Heating System 26

3.4 Water Fixtures and Appliances $\quad 27$

3.4.1 Water Fixtures $\quad 27$

3.4.2 Standard Water Home Appliances $\quad 28$

3.5 Electrical Systems $\quad 28$

3.5.1 Lighting and Fan Design 29

3.5.2 Standard Electrical Home Appliances $\quad 30$

3.5.3 Solar Photovoltaic System 31

4.0 Indoor Environmental Quality $\quad 32$ 
4.1.1 Radon $\quad 35$

4.2 Thermal Comfort $\quad 36$

4.3 Lighting and Acoustics

\begin{tabular}{ll}
5.0 & In Situ Performance \\
\hline
\end{tabular}

6.0 Intelligent Residential Systems $\quad 39$

6.1 Intelligent System Control 39

6.2 Fault Detection and Diagnosis 41

6.3 Residential System Commissioning and Best Practices 43

7.0 Data Collection and Modeling 43

8.0 On-Site Water Collection and Water Reuse Systems 45

$\begin{array}{ll}9.0 \text { Other } & 47\end{array}$

$\begin{array}{ll}\text { Acknowledgements } & 47\end{array}$

10.0 Appendix A: Contributing Organizations $\quad 49$

10.1 Appendix B: Key Reference Reports 449

10.2 Appendix C: Other Figures $\quad 51$ 


\section{List of Acronyms}

$\mathrm{ACH}, \mathrm{ACH} 50$ Air changes per hour, Air changes per hour at 50 Pascal pressure differential ARRA American Recovery and Reinvestment Act of 2009

ASHRAE American Society of Heating, Refrigerating and Air-Conditioning Engineers

BPD Buildings Performance Database

BSC Building Science Corporation

CCT Correlated color temperature

CFL Compact fluorescent lamp

cfm, cfm50 Cubic feet per minute, cubic feet per minute at 50 Pascal pressure differential

CHP Combined Heat and Power

COP Coefficient of performance

CRI Color rendering index

Cx Commissioning

DC/AC Direct current/alternating current

DOE United States Department of Energy

DHW Domestic hot water

ECM Electronically commutated motor

EF Energy factor

EgUSA EnergyGauge USA

EPA United States Environmental Protection Agency

ERV Energy (Or Enthalpy) recovery ventilator

EV Electric Vehicle

FDD Fault detection and diagnosis

gpm Gallons per minute

gpf Gallons per flush

GSHX Ground source heat exchange

GSHP Ground source heat pump 


$\begin{array}{ll}\text { HDPE } & \text { High Density Polyethylene } \\ \text { HERS } & \text { Home Energy Rating System } \\ \text { HP } & \text { Heat pump } \\ \text { HRV } & \text { Heat recovery ventilator } \\ \text { HSPF } & \text { Heating seasonal performance factor } \\ \text { HVAC } & \text { Heating, ventilation and air conditioning } \\ \text { HVI } & \text { Home Ventilating Institute } \\ \text { IAQ } & \text { Indoor air quality } \\ \text { IDEF } & \text { Integration Definition } \\ \text { IECC } & \text { International Energy Conservation Code } \\ \text { IEQ } & \text { Indoor environmental quality } \\ \text { in.w.g. } & \text { Inch water gauge } \\ \text { L/f } & \text { Liters per flush } \\ \text { LCC } & \text { Lifecycle cost } \\ \text { LED } & \text { Light-emitting diode } \\ \text { LEED } & \text { Leadership in Energy and Environmental Design } \\ \text { LID } & \text { Low Impact Design } \\ \text { MEL } & \text { Miscellaneous electric load } \\ \text { MEP } & \text { Mechanical, electrical, and plumbing } \\ \text { NIST } & \text { National Institute of Standards and Technology } \\ \text { NZ/NZE } & \text { Net-Zero/Net-Zero Energy } \\ \text { NZERTF } & \text { Net-Zero Energy Residential Test Facility } \\ \text { OEM } & \text { Original Equipment Manufacturer } \\ \text { PV } & \text { Photovoltaic } \\ \text { Rhvac } & \text { Residential HVAC (software from EliteSoft) } \\ \text { RTD } & \text { Resistance temperature detector } \\ \text { SEER/EER } & \text { Seasonal Energy Efficiency Ratio/ Energy Efficiency Ratio }\end{array}$


UFAS Uniform Federal Accessibility Standards

US United States

VOC/SVOC Volatile organic compound/Semi volatile organic compound

W/W Watts per Watt

WiFi Wireless local area network

XPS Extruded polystyrene 


\section{List of Figures}

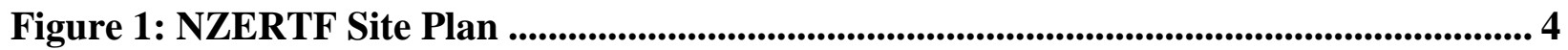

Figure 2: East Elevation with Summer \& Winter Solstice ...................................................... 10

Figure 3: NZERTF Roof Section (from Construction Set) ....................................................... 11

Figure 4: NZERTF Foundation Wall Section (from Construction Set) .................................. 12

Figure 5: Schematic of Make-up Air System ................................................................................. 22

Figure 6: Schematic of Solar Thermal and Heat Pump Water Heater ................................ 25

Figure 7: Building Enclosure Components with Nominal R-value ..................................... 51

Figure 8: Top of Foundation Wall (from Construction Set)................................................ 52

Figure 9: Heat Pump Refrigerant Circuiting and Instrumentation .................................... 53

Figure 10: Ground Source Heat Exchanger and Instrumentation Schematic........................ 54 


\section{List of Tables}

Table 1: Estimated Renewable Net-Zero Energy Requirements ............................................... 5

Table 2: First Year Renewable Net-Zero Energy Requirements ............................................ 5

Table 3: Insulation R-values $\left[\mathrm{m}^{2} \cdot \mathrm{K} / \mathrm{W}\left(\mathrm{ft}^{2} \cdot \mathrm{h}^{\circ} \mathrm{F} / \mathrm{Btu}\right)\right]$ by Component ....................................... 6

Table 4: Exterior Window Distribution........................................................................................ 9 


\section{Introduction}

\subsection{Background and Purpose}

In 2009, the National Institute of Standards and Technology (NIST) received American Recovery and Reinvestment Act funding for the construction of the Net-Zero Energy Residential Test Facility (NZERTF). The facility was designed to appear similar to homes in surrounding communities, offer the modern amenities typically found in single-family housing, and meet the needs of a typical family of four while achieving net-zero site energy use on an annual basis. Net-zero energy use was accomplished through the combination of low space-conditioning loads due to a high-performance envelope, efficient heating, cooling, and ventilation systems, lowenergy lighting fixtures and appliances, and site-generated renewable energy using both solar photovoltaic and solar thermal systems. Building Science Corporation (BSC), a building science consulting and architecture firm, worked with NIST to develop the extensive architectural and mechanical design specifications of the NZERTF. BSC's work was partially funded by the U. S. Department of Energy's Building America program. ${ }^{1}$

Following the successful one-year demonstration of net-zero site energy use ${ }^{2}$ (July 1, 2013 to June 30, 2014), the facility will be used as a research laboratory to develop new/improved test methods and performance metrics for energy efficient building technologies and renewable energy systems. The facility will also serve as a test bed to evaluate innovative building materials, components, and systems.

This report outlines potential research and development projects the findings of which will lead to more energy efficient residential buildings, improved indoor air quality, enhanced operating strategies, and new/improved methods of test that better capture "real world" performance. The report is organized in sections, with the beginning of each section describing a component or attribute of the NZERTF followed by the potential research and development (R\&D) topics that would utilize that particular attribute or component.

\subsection{Overview of the Investigative Process}

The investigative process for the findings in this report involved interviews with technical and professional individuals with knowledge and experience in high-performance residential and commercial buildings.

Through research and interviews, the study aimed to answer the following questions:

- How would you use the NZERTF as a research facility to advance residential building technologies?

- What areas of research would be most important to undertake immediately or in the

\footnotetext{
${ }^{1} \mathrm{http}: / /$ www.eere.energy_gov/buildings/building_america

${ }^{2}$ Bello, M., NIST Test House Exceeds Goal; Ends Year with EnergytTo Spare, Laboratory Design, July $22,2014$. http://www.labdesignnews.com/videos/2014/07/nist-test-house-exceeds-goal-ends-year-energy-spare
} 
future?

- What questions or gaps in current knowledge for residential high-performance building technologies are most pressing?

- In addition to examining energy performance, what other high-performance building R\&D topics can or should be performed?

- What are the challenges and performance requirements for continued growth and success of high-performance residential buildings?

Content derived from these conversations was documented and used for $R \& D$ Opportunities described within this document. Appendix A contains the complete list of contributing organizations.

\subsection{Definitions: What is a net-zero energy house?}

A zero energy house is one in which all energy needs of the house are met using energy that is generated on-site using renewable sources. ${ }^{3}$ A net-zero energy house is one in which the total amount of energy consumed in a year is less than or equal to the total amount of energy generated on-site during that year. While meeting the goal of net-zero energy is less difficult than the more stringent zero energy goal - where the house is independent of all off-site energy sources and must have the capability to store energy on the site - it still requires a significant energy reduction effort. A net-zero energy home requires some form of on-site energy generation, be connected to the electrical grid, and use the grid as "storage" for the site-generated energy that is not immediately consumed.

New building materials and building techniques as well as availability of more efficient equipment, appliances, and renewable energy systems have made construction of net-zero energy (NZE) and low energy houses possible. Many low energy houses are being built and there are a number of case studies that demonstrate that net-zero energy use is being achieved. ${ }^{4}$ As new technologies and design strategies become available, performance and reliability of low energy homes will continue to improve.

For a low energy house, a significant portion of the total annual energy consumption can be attributed to the lifestyle of the home's occupants rather than the design of the house. For example, the heating and cooling temperature setpoints and the use of miscellaneous electric loads (MELs) - also called plug loads — are primarily a function of the desires/activities of the occupants of the house rather than the low energy characteristics of the house and building systems. For this reason, it is more accurate to refer to the design of a new house as being netzero energy capable rather than being net-zero energy.

\footnotetext{
${ }^{3}$ See ASHRAE Vision 2020, American Society of Heating, Refrigerating and Air-Conditioning Engineers, page 4, January 2008.

${ }^{4}$ Ueno, K.; Wytrykowska, H. and Bergey,D.,’Transformations, Inc.: Partnering to Build Net-Zero Energy Houses in Massachusetts,” BSC: BA-1303, 2013, http://www.buildingscience.com/index_html.
} 
The term "net-zero energy" as used in this paper could theoretically refer to either net-zero (NZ) site energy or to net-zero source energy. ${ }^{5}$ Energy use reduction is the goal in either case, but the calculation used to determine energy consumption for site energy is based only on energy use at the site whereas source energy use takes into account the energy used to generate and to deliver energy to the site as well as what is used at the site. Source energy consumption more accurately reflects the environmental impact of energy use. ${ }^{6}$

\section{NZERTF General Information}

\subsection{Climate, Site, Form, and Orientation}

The facility is located in Gaithersburg, MD in climate zone 4A (Mixed Humid). The general criteria for this climate zone are as follows: more than $508 \mathrm{~mm}$ (20 in) annual precipitation, less than or equal to 4500 cooling degree-days at $10^{\circ} \mathrm{C}\left(50^{\circ} \mathrm{F}\right)$ basis and less than or equal to 5400 heating degree-days at $18^{\circ} \mathrm{C}\left(65^{\circ} \mathrm{F}\right)$ basis. While the heating load often predominates in a mixed humid climate, the cooling and humidity loads are also significant.

The site for the house is a large south-facing lot that rises about $3 \mathrm{~m}(10 \mathrm{ft})$ above the road within the first $30.5 \mathrm{~m}(100 \mathrm{ft})$. The slope is less steep in the other directions. There are mature trees along the east and west edges of the site. Since solar energy is the renewable energy source used to meet the net-zero energy goal, shading studies of the site were performed by NIST (see Figure 1). Electricity, communication cable, natural gas, water, sewer, and storm drainage are available at the site. During the net-zero energy demonstration phase, the house was configured as an allelectric house. Immediately surrounding the house are three different types of geothermal loops sized to meet the thermal load requirements of the NZERTF that will be used in future research projects. (See also Appendix C: Figure 10)

The relatively compact footprint and volume of the house contributes to energy efficiency primarily due to a low surface area to volume ratio. Even though this type of house can accommodate nearly a full second floor, the roof configuration lowers the overall profile of the house and reduces the exposed wall surface area.

With solar energy as the renewable energy source, south-facing sloped surfaces were used to mount the solar thermal and solar photovoltaic panels. The 4:12 pitch sloped roof of the shed dormer across the front of the house provides a fully unshaded surface and was utilized for the $10.2 \mathrm{~kW}$ photovoltaic system. The roof of the porch (also 4:12 pitch) was used as the mounting surface for four solar thermal collectors.

\footnotetext{
${ }^{5}$ Torcellini, P.; Pless, S.; Deru, M. and Crawley, D., "Zero Energy Buildings: A Critical Look at the Definition," National Renewable Energy Laboratory, NREL/CP-550-39833, June 2006, http://www.nrel.gov/docs/fy06osti/39833.pdf.

${ }^{6}$ Ueno, K. and Straube, J., "Understanding Primary/Source and Site Energy," BSC: BSD-151, 2010, http://www.buildingscience.com/index_html.
} 
The south-facing roof of the detached garage, that is located to the west side of the house, provides additional space for solar panels. For the demonstration phase, the 9.5:12 pitch sloped garage roof was not used for solar photovoltaic or thermal panels but could be utilized for future research projects.

The interior of the house includes a typical modern kitchen at the rear with adjacent dining area, a living room at the front, a master bedroom suite on the second floor, three additional bedrooms one of which is on the first floor and can be used as an office, and three full bathrooms. The total interior living space is about $250.8 \mathrm{~m}^{2}\left(2700 \mathrm{ft}^{2}\right)$. Beneath the living space is a $139.3 \mathrm{~m}^{2}(1500$ $\mathrm{ft}^{2}$ ) full unfinished basement. This style of house with a similar interior layout can be found throughout the mid-Atlantic region as well as in New England.

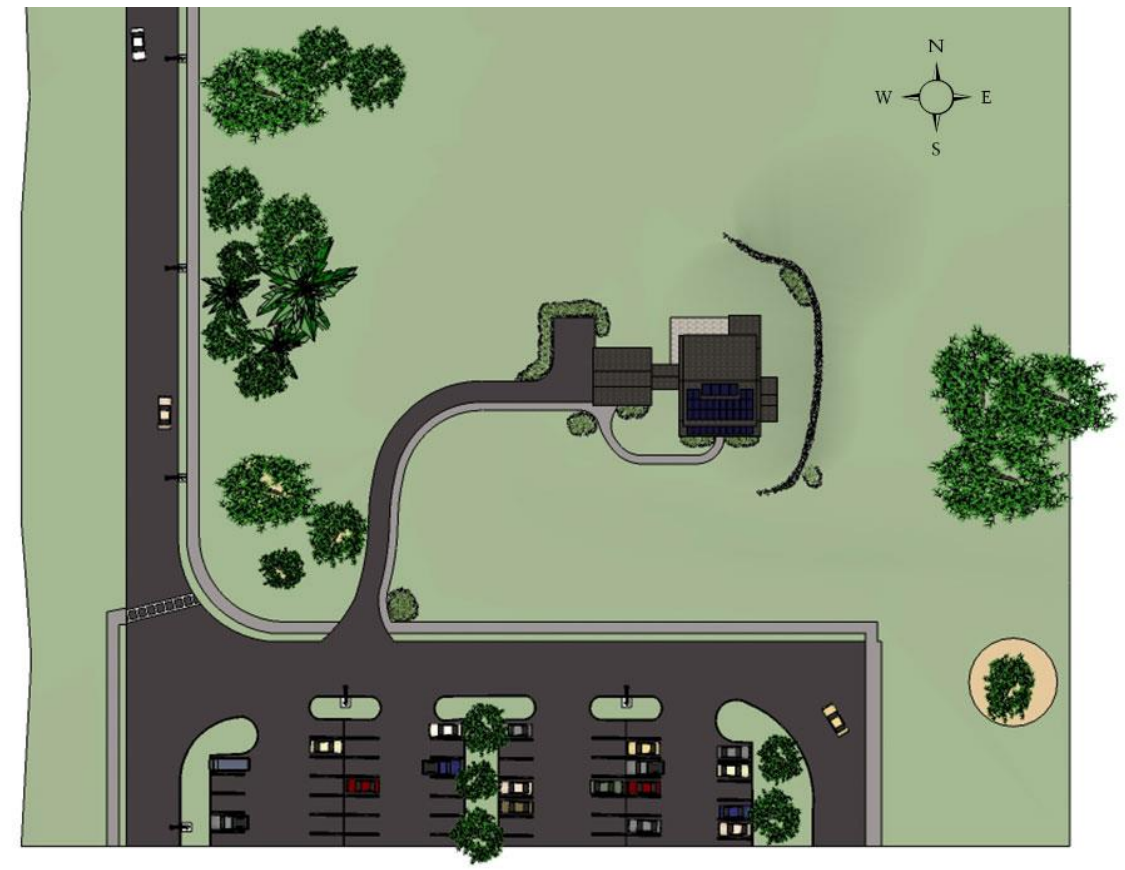

Figure 1: NZERTF Site Plan

\subsection{Renewable Net-Zero Energy Requirements}

For a net-zero site energy capable house, the renewable energy system needs to be designed so that it produces at least as much energy on a yearly basis as is consumed on site. For a new house, the predicted energy consumption is determined by developing an energy model for the house. At design completion of the NZERTF, the updated EnergyGauge USA (EgUSA) software model projected energy consumption of $12405 \mathrm{kWh} /$ year. To meet the projected consumption (see Table 1), the final design specified thirty-two $320 \mathrm{~W}$ panels mounted at an 18.4 degree tilt (roof slope of 4:12) for a $10.24 \mathrm{~kW}$ system with a predicted output of $14800 \mathrm{kWh} /$ year. $^{7}$

\footnotetext{
${ }^{7}$ Ueno, K., Memo: NIST NZERTF Zero Energy Performance, October 28, 2009.
} 


\begin{tabular}{|l|r|r|}
\hline Predicted & $k$ Wh/year & \% of total \\
\hline Heating & 3305 & $26.6 \%$ \\
\hline Cooling & 519 & $4.2 \%$ \\
\hline Water Heating & 1028 & $8 \%$ \\
\hline Lights & 1274 & $10.3 \%$ \\
\hline Appliances & 2440 & $19.7 \%$ \\
\hline Plug Loads & 3839 & $30.1 \%$ \\
\hline
\end{tabular}

Table 1: Estimated Renewable Net-Zero Energy Requirements

During the first year of operation ${ }^{8}$, the residence generated $13523 \mathrm{kWh}$ of electricity using the $10.2 \mathrm{~kW}$ solar photovoltaic system and total energy consumed was $13039 \mathrm{kWh}$ while meeting the electrical and comfort needs of a typical four member family. The solar photovoltaic system converted 16.8 percent of the incident solar radiation into useful electrical energy. The solar thermal hot water system provided 54 percent of the energy required to meet the domestic hot water load. The actual yearly energy consumption by major category for the facility in its first year demonstration phase follows below in Table 2.

\begin{tabular}{|l|r|r|}
\hline Actual & $k W h /$ year & \% of total \\
\hline Heating & 3796 & $30 \%$ \\
\hline Cooling & 2375 & $18 \%$ \\
\hline Water Heating & 1432 & $11 \%$ \\
\hline Lights & 435 & $3 \%$ \\
\hline Appliances & 1867 & $15 \%$ \\
\hline Plug Loads & 2440 & $19 \%$ \\
\hline HRV & 514 & $4 \%$ \\
\hline
\end{tabular}

Table 2: First Year Renewable Net-Zero Energy Requirements ${ }^{9}$

\section{Major Building Components in the Net-Zero Energy House}

Major building components of the NZERTF that affect its performance include the building enclosure (or envelope), space conditioning systems including central heating, cooling, and ventilation, electrical systems, and appliances. Included in the section are the alternate space conditioning and air distribution systems installed for research purposes, but not currently operational.

\footnotetext{
8 The metrological winter (Dec. - Feb.) for 2013/14 was colder $\left(-0.44{ }^{\circ} \mathrm{C}\left[-0.8{ }^{\circ} \mathrm{F}\right]\right)$ and snowier $(+9.2 \mathrm{~cm}[+3.62$ in]) than the normal (see Meteorological Winter and February Both Colder Than Normal With Above Normal Snow, Washington Post, March 5, 2014) increasing energy demands for heating and lowering energy production from solar photovoltaic and thermal systems during that period.

${ }^{9}$ Total Energy Consumed is measured using a device having a greater accuracy than the devices used to measure the individual end uses. Thus a small difference $(<1.5 \%)$ between the reported Total Energy Consumed and the sum of monthly values for each individual end uses may exist."
} 


\subsection{Building Enclosure/Envelope}

In this subsection are discussed the general exterior design considerations on the building enclosure/envelope that impact the energy efficiency and durability of the house.

\subsubsection{Building Enclosure Design}

The design of the building enclosure is the single most important factor in the design of a high performance building since this is the only contribution that the building itself can make towards controlling energy use. The design specifies all layers and materials that make up the physical separation between inside and outside. In particular, the enclosure design must include the design of the four control systems required of the enclosure: water, airflow, vapor, and thermal control systems. Continuity of each of the control layers - water, airflow, vapor, and thermal — is important for the performance and reliability of the enclosure.

The water and vapor control systems are required for the durability of the enclosure and for indoor environmental quality. The airflow and thermal control systems reduce heat transfer between the interior and the exterior and thus control much of the heating and cooling load of the house. The basic approach to the building enclosure design for the NZERTF was to clearly specify each of the control layers for each component of the enclosure and then to design the details of the connections between components to create continuous and complete systems for each control function.

Insulation is the primary material in the thermal control system. The thermal resistance of the installed insulation as quantified by the R-value is the most widely used measure of heat loss through the enclosure. Achieving high R-values is a necessary part of any high performance enclosure design strategy. Table $\mathbf{3}$ shows the design R-values of the various building envelope components for the NZERTF. For the above-grade components, the R-values for the NZERTF are nearly two times that called for by the prescriptive 2012 International Energy Conservation Code $(\text { IECC) })^{10}$.

\begin{tabular}{|l|l|l|l|l|l|}
\hline & Sub-Slab & Fdn Wall & Ext Wall & Windows & Roof \\
\hline $\begin{array}{l}\text { Prescriptive 2012 IECC } \\
\text { nominal R-value }\end{array}$ & 1.8 (US 10) & 1.8 (US 10) & 3.5 (US 20) & 0.5 (US 2.8) & 6.7 (US 38) \\
\hline $\begin{array}{l}\text { NZERTF nominal R- } \\
\text { value }\end{array}$ & 1.8 (US 10) & 4.1 (US 23) & 7.9 (US 45) & 0.9 (US 5.2) & 12.7 (US 72) \\
\hline
\end{tabular}

Table 3: Insulation R-values $\left[\mathrm{m}^{2} \cdot \mathrm{K} / \mathrm{W}\left(\mathrm{ft}^{2} \cdot \mathrm{h}^{\circ} \mathrm{F} / \mathrm{Btu}\right)\right]$ by Component

More than half of the installed above-grade insulation is applied to the exterior side of the structure in a continuous thermal control layer.

${ }^{10}$ International Code Council (ICC). 
The cross section of NZERTF building enclosure appearing in Appendix C: Figure 7 shows the building enclosure components, the nominal R-value of the components and, except for the window and door, the primary location of the water, airflow, vapor and thermal control functions for each component.

\section{Research and Development Opportunities - Enclosure}

- Examine diagnostic measurement and identification techniques (e.g., low cost sensors) to quantify energy losses associated with thermal envelope components. Characterize energy losses in the enclosure and generate data for energy modeling purposes.

- Characterize the performance degradation of the thermal envelope over time:

$\circ$ Characterize the performance degradation for insulation materials and deterioration rates for door and window seals and connection assemblies.

- Identify and characterize changes in air infiltration as a result of the aging or failing sealant materials that shrink or lose elasticity.

- Identify and characterize long-term performance metrics that assess the suitability of different envelope systems and materials under real-life operating conditions.

- Test the performance of the building enclosure to determine if moisture has penetrated the enclosure/cavities:

○ Define procedures and identify technologies (e.g., infrared measurement, visual inspection, core sampling) for detecting moisture in the wall systems, measuring moisture profiles under sheathing, and developing baselines and assessment/measurement approaches.

- Investigate effects of transient material quality (e.g., water and air degradation effects) on air barrier systems.

- Capture building envelope data supportive of improving the accuracy of building model performance including:

- Data on ground heat loss, especially for highly insulated foundation and floors.

- Infrared sensing test equipment and methodologies that enable in situ testing and data collection of the thermal resistance of constructed walls, roofs, and foundations.

- Procedures appropriate for assessing the thermal performance of existing buildings/retrofits and for quality control use in new construction.

- Use of in situ measurement techniques to capture the thermal resistance of existing wall assemblies.

- Investigate economic models, decision support capabilities, and cost/benefit analysis for enclosure designs and performance.

- Develop a standard method of test for post-occupancy building energy use.

- Quantify, for a tight building envelope, the wind/weather effects on infiltration using interior sensors and exterior weather monitoring equipment.

- Experimentally determine whether the extended-length fasteners used for siding attachment are at higher risk of failure from wind/severe weather events. 
- Experimentally determine performance of highly impermeable membranes used for building wraps relative to semi-permeable membranes for enclosure moisture management. Determine the preferred sealing approach at the wall/slab interface for onslab structures.

- Experimentally determine performance of open-cell and closed-cell spray insulation for moisture management in attic spaces and roof systems.

\subsubsection{Enclosure Airtightness}

The airtightness of the enclosure is determined by pressurizing and depressurizing the interior of the home using a blower door fan and measuring the amount of air delivered by the fan to maintain specific pressure differentials. Five different blower door tests were conducted on the NZERTF during various stages of construction. The first test for airtightness was made after the exterior plywood sheathing and continuous air/moisture barrier was installed. The exterior openings of the door and window plywood extension boxes - used to accommodate the $10.2 \mathrm{~cm}$ (4 in) of polyisocyanurate foam - and all above-grade penetrations were sealed from the outside; the openings of all below-grade penetrations were sealed on the inside. Since this test was conducted prior to the installation of the window and door assemblies, sheets of polyisocyanurate foam were used to fill these cavities and tightly sealed against the adjoining framing elements. The blower door fan was used to depressurize the house to a $50 \mathrm{~Pa}$ difference relative to the outside and to measure the airflow in cubic feet per minute required to maintain the $50 \mathrm{~Pa}$ pressure differential (cfm50).

The result of the first airtightness test was quite remarkable: $117 \mathrm{~m}^{3} / \mathrm{h}$ at $50 \mathrm{~Pa}(69 \mathrm{cfm} 50)$. Using $1270 \mathrm{~m}^{3}\left(44864 \mathrm{ft}^{3}\right)$ as the volume of the house, ${ }^{11}$ this corresponds to 0.09 air changes per hour at $50 \mathrm{~Pa}$ differential (ACH50). The final measurement for the completed facility with the heat recovery ventilation inlet and outlet sealed and the kitchen and dryer vents operational and not sealed was $802 \mathrm{~m}^{3} / \mathrm{h}$ at $50 \mathrm{~Pa}(470 \mathrm{cfm} 50)$, well below ( $<25$ percent) the Building America target of $3432 \mathrm{~m}^{3} / \mathrm{h}$ at $50 \mathrm{~Pa}$ and lower than the designed NZERTF target value for airtightness of $1900 \mathrm{~m}^{3} / \mathrm{h}$ at $50 \mathrm{~Pa}$.

\section{Research and Development Opportunities - Enclosure Airtightness}

- Airtightness measurement:

$\circ$ Investigate and validate standardized test specifications and calibration metrics for assessing the permeability of a building's enclosure.

- Develop faster and more accurate test methods/standards that can be utilized in the construction and use phases.

- Develop test methods and models for leakage rates:

○ Verify leakage rates.

- Refine testing procedures and models based upon climate, quality of construction, and the geometry of the home.

\footnotetext{
$1144864 \mathrm{cu} f t$ is the volume that was calculated by the LEED for Homes provider.
} 
- Verification of blower door results over time:

- Determine whether blower door test results change over time due to aging and deterioration.

- Determine impact of debris accumulation in door and window jams on blower door test results.

- Determine adequacy of current blower door tests and number/frequency needed to fully characterize leakage rates.

- Establish metrics and generate data on changes in sealing effectiveness.

- Compare blower door test results to results obtained using tracer gas techniques.

- Examine secondary effects of very airtight enclosures:

- Determine whether increased air tightness of the envelope increases other energy penalties while also reducing energy losses due to infiltration.

- Quantify the effects of enclosure tightness on the broader performance metrics.

- Determine the effects of building tightness on appliance performance.

- Investigate changes in airflow in living spaces for a tight NZE enclosure and their effects on indoor air quality and potential life safety issues (e.g., timely detection of the presence of hazardous gases).

- Develop the economic cost benefit analysis for NZE enclosures incorporating the upfront costs of construction, and full lifecycle costs for energy consumption and mechanical ventilation requirements.

- Identify and document new/additional costs incurred by tight envelopes including systems providing makeup air for appliances and exhaust fans.

- Investigate the secondary effects and economics of combustible fuel (e.g., natural gas (NG)) range tops and heating appliances on ventilation/direct venting requirements for tight high-performance residential building enclosures.

\subsubsection{Location, Type and Size of Windows}

With the house placed on the site to maximize solar exposure, techniques for controlling solar heat gain were considered while determining the number, location and size of the windows. Table 4 shows the distribution of the total window area over the exterior walls.

\begin{tabular}{|l|l|l|l|l|l|}
\hline & North & South & East & West & Total \\
\hline $\begin{array}{l}\text { Surface area of } \\
\text { exterior wall }\end{array}$ & $71.3 \mathrm{~m}^{2}$ & $71.3 \mathrm{~m}^{2}$ & $83.7 \mathrm{~m}^{2}$ & $83.7 \mathrm{~m}^{2}$ & $310 \mathrm{~m}^{2}$ \\
\hline $\begin{array}{l}\text { Total area of } \\
\text { glazing }\end{array}$ & $\left(767 \mathrm{ft}^{2}\right)$ & $\left(767 \mathrm{ft}^{2}\right)$ & $\left(901 \mathrm{ft}^{2}\right)$ & $\left(901 \mathrm{ft}^{2}\right)$ & $\left(3336 \mathrm{ft}^{2}\right)$ \\
\hline $\begin{array}{l}\text { glazing percentage } \\
\text { of surface area }\end{array}$ & 16.4 & $16.5 \mathrm{~m}^{2}$ & $6.2 \mathrm{~m}^{2}$ & $4.2 \mathrm{~m}^{2}$ & $38.6 \mathrm{~m}^{2}$ \\
$\left(126 \mathrm{ft}^{2}\right)$ & $\left(178 \mathrm{ft}^{2}\right)$ & $\left(67 \mathrm{ft}^{2}\right)$ & $\left(45 \mathrm{ft}^{2}\right)$ & $\left(416 \mathrm{ft}^{2}\right)$ \\
\hline
\end{tabular}

Table 4: Exterior Window Distribution 
In a mixed humid climate, solar gain through south-facing windows can lower the heating load during the winter but increase the cooling load in the summer. The general guideline in this climate is to place south-facing windows so that they are fully blocked in the summer to prevent solar heat gain but exposed to allow solar heat gain in the winter. For the NZERTF design, there is more glazing on the south facade than on any other side. The windows on the $2^{\text {nd }}$ floor and in the living area extension to the east are directly below an overhang; the depth of overhang is designed so that the summer sun at its solstice is totally blocked by the overhang whereas the winter sun at its solstice reaches the entire window. The first floor south-facing windows along the main section of the house (about 44 percent of the south-facing glazing) are fully shaded in the summer by the roof of the front porch; during the winter, about 50 percent of that glazing is unshaded (see Figure 2). The windows were installed in a manner that makes removal and installation of the fenestration units possible with minimum disruption to other building elements.

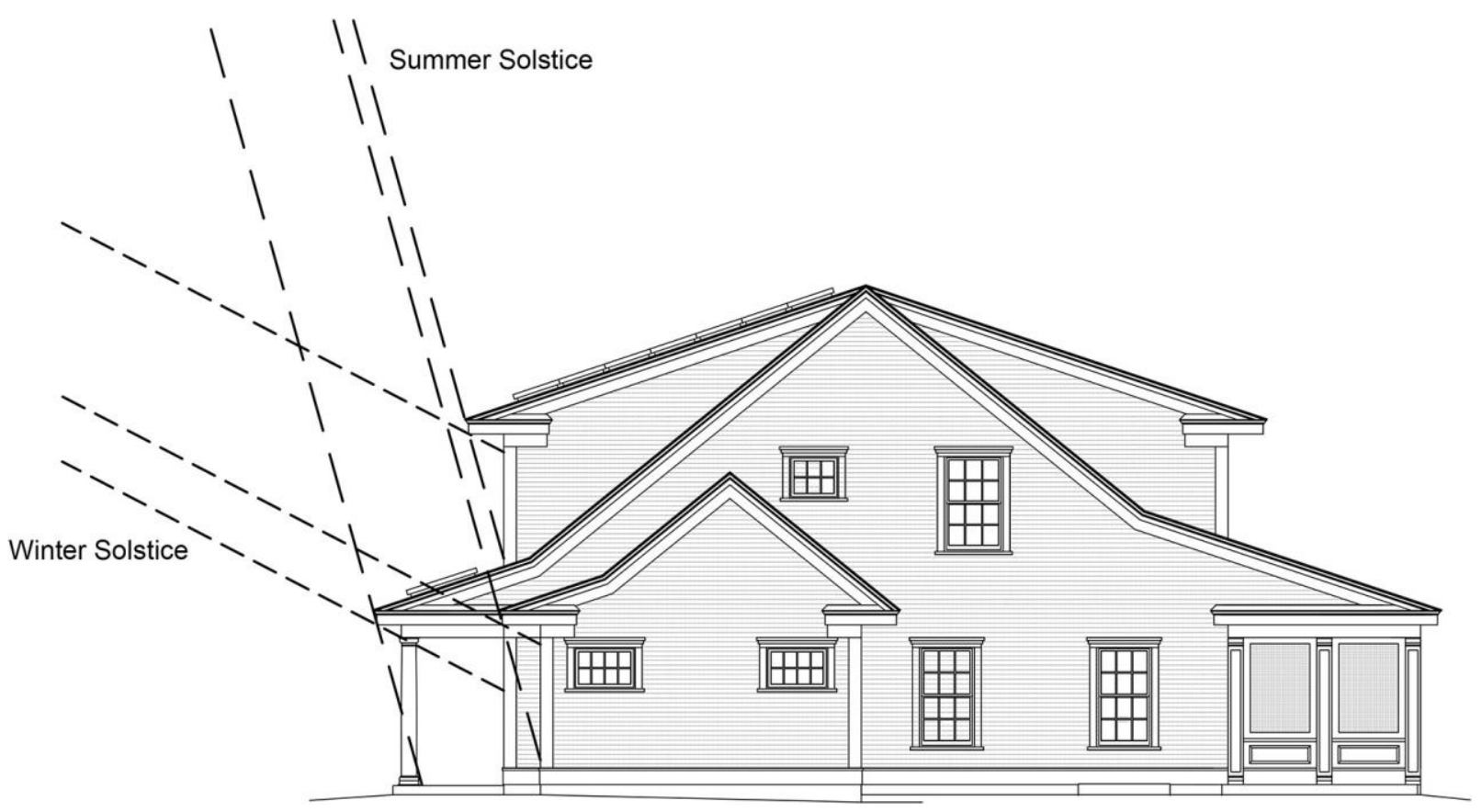

Figure 2: East Elevation with Summer \& Winter Solstice

\section{Research and Development Opportunities - Windows}

- Identify and evaluate alternative glazing options for south, north, east, and west facing windows to lower the heating load during the winter and cooling load in the summer based upon their solar orientation. Document installed costs and measured performance.

- Install and measure the energy impact of advanced glazing/window product technologies. 


\subsubsection{Conditioned Attic and Basement}

Since both the attic and the basement contain mechanical equipment, they are included as part of the conditioned space. Heating, cooling, ventilation, and hot water equipment as well as ductwork are located in the basement. The inverters for the solar panels and some ductwork are located in the attic. The basement is actively conditioned with air supply diffusers whereas the attic is conditioned through transfer vents between the $2^{\text {nd }}$ floor and the attic.

\section{Roof Structure}

The material layers of the NZERTF roof assembly from exterior to interior are as follows:

- Asphalt roof shingles;

- Fully adhered roof membrane (water control) over plywood roof sheathing;

- Three layers of foil-faced polyisocyanurate insulating sheathing with seams staggered and taped on the middle layer (thermal and vapor control);

- Fully-adhered air barrier membrane (airflow control) applied to plywood sheathing over rafters;

- Cellulose cavity insulation (additional thermal control);

- Interior gypsum wallboard with seams taped (in attic).

These layers can be seen in the roof section shown in Figure 3.

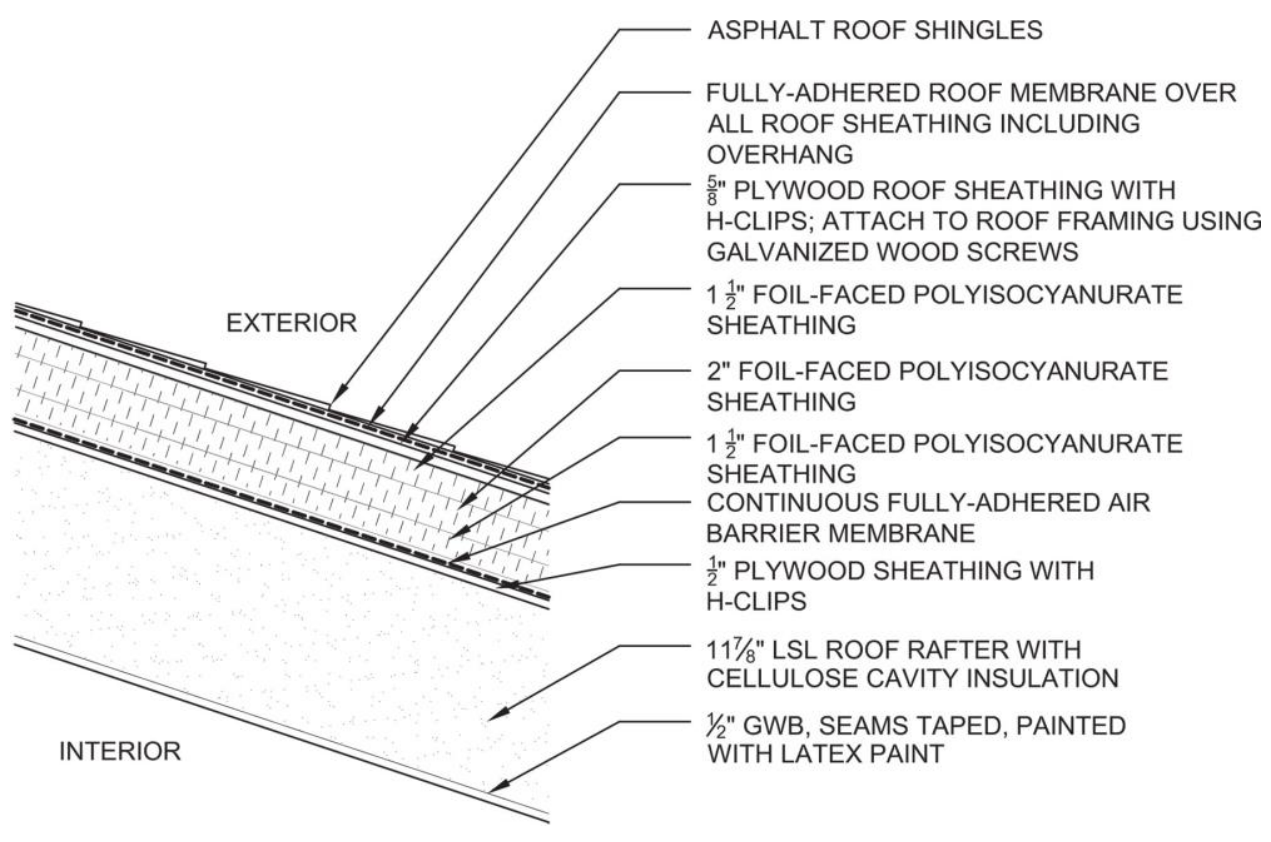

Figure 3: NZERTF Roof Section (from Construction Set)

\subsubsection{Foundation Wall}

To reduce the effect of the thermal bridge, the NZERTF design called for a layer of exterior insulation to be applied to the exterior face of the upper part of the foundation wall extending to below-grade (see Appendix C: Figure 8). The exterior insulation is protected above-grade by an aluminum coil stock cover. 
The foundation walls and basement slab complete the lower part of the building enclosure. As with the other parts of the building enclosure, the four control systems - water, airflow, vapor and thermal control - are required.

The material layers for the foundation wall, from exterior to interior, are as follows:

- Free draining backfill (water control);

- Geocomposite drainage board (water control);

- Dampproofing (water control);

- Concrete wall (airflow control);

- XPS insulation (thermal and vapor control);

- Foil-faced polyisocyanurate insulating sheathing with seams taped (thermal, vapor and airflow control);

- Gypsum wallboard.

These layers can be seen in the foundation wall section shown in Figure 4.

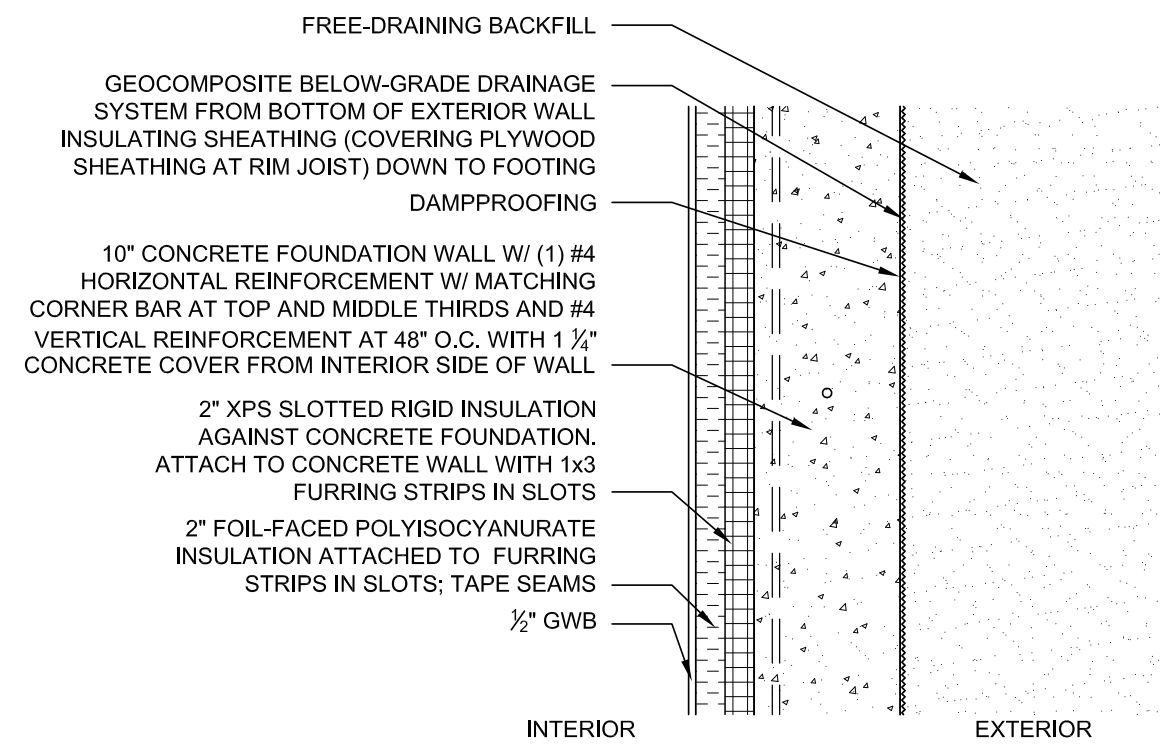

Figure 4: NZERTF Foundation Wall Section (from Construction Set)

\section{Research and Development Opportunities - Conditioned Attic and Basement}

- Identify envelope data appropriate to improve the accuracy of building model performance including:

○ Data on ground heat loss, especially for highly insulated foundations and high building density/adjacent heat sources

- Develop/improve infrared-sensing test equipment and methodologies that enable onsite/ in situ testing of the thermal resistance of walls, roofs, and foundations.

- Detect and monitor latent heat and moisture condensation in highly insulated conditioned attic and basement areas for Climate Zone 4A - Mixed Humid.

- Measure the heat load effects of roof-mounted photovoltaic (PV) collector covering a large portion of the south facing roof and conditioned attic space. Characterize the effects 
and generate the data for representing the impacts of PV shading on heating/cooling relative to a cool roof rating established by the Cool Roof Rating Council.

- Investigate the NZERTF building site, orientation, and roof design and their combined effect on seasonal predicted PV performance due to the accumulated and persistent snow load, as evidenced during the first-year demonstration phase.

\subsection{Space Conditioning Systems}

The purpose of space conditioning is to provide a comfortable and healthy indoor environment by maintaining the temperature, the humidity, and the air quality within acceptable ranges. The functions to be provided include adding or removing heat, adding or removing humidity, replacing stale air with outdoor air, and distributing the conditioned air throughout the space. The basic strategy used in the design of the system for the NZERTF was first to make the work to be done by the system as easy as possible and then to select individual HVAC components that are simple to control and optimized for the particular function to be provided.

There are several factors involved to make the work required of the system as easy as possible. These include keeping heating and cooling loads low, controlling unintended air leakage through the enclosure, and minimizing the distance and complexity of the delivery path for distributing the air.

The main components of the conditioning system are the heating/cooling system and the ventilation system each with its own distribution and filtering system. Since the house was "allelectric" in the first-year demonstration phase, a central air split-system heat pump with integrated dehumidification was specified for heating/cooling and dehumidification, and a heat recovery ventilation (HRV) system was specified for ventilation. By keeping ventilation and heating/cooling equipment completely separate, the controls of the system are simplified and efficiencies for each system can be introduced that are consistent with the primary function of the equipment.

Heating and cooling design loads were computed from building form, orientation, room layout, and enclosure components using the software program Rhvac (Residential HVAC) from EliteSoft. This modeling program provides a room-by-room calculation using the room layout and enclosure information and user-specified parameters for infiltration, ventilation, and heat gain from appliances and people.

\subsubsection{Central Air Split System - Dedicated Dehumidifying Two-Speed Heat Pump}

The design for the all-electric central air system called for a split air source heat pump system with the following performance characteristics for the air handler and matching condensing unit:

- Seasonal Energy Efficiency Ratio (SEER) of 14.8 or better and Heating Seasonal Performance Factor (HSPF) of 8.5 or better;

- Electronically commutated motor (ECM) fan for variable supply air speed;

- Evaporator coil for use with refrigerant R-410A; 
- Supplemental electric resistance heat of $7.5 \mathrm{~kW}$;

- Modulating hot-gas condenser reheat for integrated supplemental dehumidification;

- Digital scroll compressor (for variable refrigerant flow).

A modulating hot-gas condenser reheat mechanism (see Appendix Figure 9) provides supplemental dehumidification when cooling is not needed by operating the condensing unit by directing a controlled amount of the hot gas to an indoor heating coil to reheat the cooled and dehumidified air to the neutral air temperature. ${ }^{12}$ This method of supplemental dehumidification retains the efficiency of the refrigeration cycle, avoids overcooling, and makes use of the waste heat that is generated.

\section{Research and Development Opportunities - Central Air System}

- Identify and evaluate performance of a smaller capacity central heat pump system that meets capacity requirements for the NZERTF:

- Identify required changes/additions to standard design guidance to achieve the required airflows and ventilation air requirements for each room and space.

- Evaluate distribution system effectiveness for smaller capacity HVAC systems.

- Evaluate and optimize heat pump (HP) control strategy and its use of auxiliary resistance heat. (See also Section 3.2.2 Air Source Heat Pump Systems)

- Evaluate runtimes for the dual-mode HP, latent sensing, and overall HP performance for space conditioning and dehumidification:

○ Compare the performance for heat pumps with dedicated dehumidification to conventional heat pump systems with a separate dedicated dehumidifier system.

- Quantify the impact of operating the NZERTF with multiple temperature control zones versus the one zone that was used during the initial demonstration.

- Evaluate performance of a ground source heat pump (GSHP) for the NZERTF using various earth heat exchangers and working fluids. (See also Section 3.2.7 Geothermal Heating Systems)

- Evaluate usability and performance of combustible fuel (e.g., NG or propane) heating systems for high-performance tight enclosures.

- Correlate building performance to predominant regional energy pricing structures.

- Investigate the effects of combustible fuel appliances on whole house performance, environmental and occupant comfort, and moisture/humidity levels.

- Test and field verify heat pump systems that incorporate alternative refrigerant fluids.

- Evaluate the impact of appliance heat loads on space conditioning and control systems.

\subsubsection{Air Source Heat Pump System}

Heat pump (HP) systems provide the primary heating and cooling for the NZERTF. The heating and air conditioning system used for the first year of operation in the NZERTF consists of an air

\footnotetext{
${ }^{12}$ AAON, Inc.
} 
source heat pump with dedicated dehumidification. Special control algorithms and a hot gas bypass design with an additional indoor air heat exchanger that reheats the dehumidified air provide the dedicated dehumidification function, available in the cooling mode. The outdoor unit incorporates a two-speed scroll compressor with two modulated hot gas valves on the compressor discharge that send hot refrigerant gas through a third pipe to the reheat heat exchanger during active dehumidification. A supply air temperature sensor provides the control signal used to proportionally modulate the flow of hot refrigerant gas to maintain a preset supply temperature during dedicated dehumidification. The indoor air handler unit contains a variable speed indoor fan. (See Appendix C: Figure 9).

Rating conditions ${ }^{13}$ from the Air-Conditioning, Heating, and Refrigeration Institute (AHRI) estimate the cooling capacity as $7.60 \mathrm{~kW}$ and the coefficient of performance (COP) as 3.82. In the heating mode at AHRI rating conditions, the unit has a heating capacity of $7.80 \mathrm{~kW}$. The unit has a seasonal energy efficiency ratio (SEER) of $4.63 \mathrm{~W} / \mathrm{W}$ and a heating seasonal performance factor (HSPF Region IV) of 2.65 W/W.

Alternative heat pump technologies can be tested and evaluated in the facility including groundsource, mini-split heat pumps systems, and integrated (heat pump and domestic hot water systems) (see also Section 3.2.4 Support for Alternate Conditioning Systems, Section 3.2.7 Geothermal Heating Systems, and Section 3.3.2 Auxiliary Heat Pump Water Heating System).

\section{Research and Development Opportunities - Air Source Heat Pump Systems}

- Evaluate the performance effects of varying latent loads on HP dehumidification performance:

○ Examine varying ratios of sensible to latent loads (e.g., 80/20 vs. 50/50) on overall HP performance and calculate dual-mode HP performance for specific climate zones.

- Identify and quantify internally generated latent loads and their relative effect on overall HP performance within a specific climate zone.

- Compare the efficiency/performance of utilizing dedicated HP dehumidification performance to a single-mode (heating/cooling) heat pump with a stand-alone wholehouse dehumidification system.

- Evaluate current heat pump designs, controls, and control strategies used for heat pumps that provide both space conditioning and dehumidification:

$\circ$ Analyze strategies and controls on runtimes, latent load sensing, effects on overall HP performance for space conditioning and dehumidification.

- Evaluate and optimize the current heat pump control strategy and its use of auxiliary resistance heat:

\footnotetext{
${ }^{13}$ AHRI 2008. Standard 210/240, Standard for performance rating of unitary air-conditioning and air-source heat pump equipment, Air-Conditioning, Heating, and Refrigeration Institute, 2111 Wilson Boulevard, Suite 500, Arlington, VA 22201.
} 
- Integrate and evaluate external temperature and insolation sensor input into HP control strategies.

- Integrate and evaluate utility pricing signals into HP control strategies.

- Investigate the performance of mini-split heat pump as an alternate/supplemental heating/cooling system:

- Evaluate the overall performance of a mini-split system integrated with the central air system. Determine the LCC and cost/benefit of reducing the capacity of the central air HP system when combined with a mini-split system.

- Evaluate dehumidification capabilities of mini-split heat pumps and their capacity to remove latent loads for dehumidification.

- Compare indoor temperature distribution using a mini-split heat pump system to a traditional heat-pump/air-distribution system.

- Compare and document the installed/in situ performance of an air source HP compared to a ground source HP system:

- Determine the SEER/EER rating over a broad range of outdoor ambient temperatures.

- Establish overall annual energy performance and production for each system. (See Section 3.2.7 Geothermal Heating Systems.)

- Determine the impact of a super-insulated building on the LCC for air and ground source HPs.

- Evaluate current heat pump designs, controls, and control strategies used for heat pumps that provide both space conditioning and dehumidification:

○ Analyze strategies and controls on runtime and latent load sensing on overall HP performance for space conditioning and dehumidification.

\subsubsection{Central Air Distribution Systems}

The air handling unit, located in the southeast quadrant of the basement, has T-shaped supply and return trunks - the north-south trunks connect to the air handler with stem trunks running to the west. All ductwork material is sheet metal and the supply trunk is insulated. During the demonstration phase, the conditioned air was supplied by high wall or ceiling diffusers. Runouts, without branching, are routed from the supply trunk to each of the rooms in as direct a path as possible passing through walls, chases and the open-web floor trusses. An air return is provided on the east and on the west ends of each of the habitable floors. Transfer grilles over the bedroom and office doors and between the basement and first floor are also part of the return air system.

The designed airflow for the NZERTF is $2039 \mathrm{~m}^{3} / \mathrm{h}(1200 \mathrm{cfm})$. With this design, airflow distribution requirements to the individual rooms are based on the calculated heating and cooling loads and used for the subsequent ductwork design. All of the supply air ductwork, except for the basement, is sized based on the airflow for cooling. To ensure that sufficient heating will be provided in the basement, the basement airflow is adjusted to be consistent with the heating to cooling airflow ratio for the other spaces. The supply air ducts are sized to keep the run-out velocity below $2.54 \mathrm{~m} / \mathrm{s}(500 \mathrm{ft} / \mathrm{min})$. 


\section{Research and Development Opportunities - Central Air Distribution Systems}

- Develop the metrology to quantify installed/in situ performance of air distribution systems:

○ Develop appropriate measures to quantify performance of air distribution systems.

$\circ$ Assess the effects on the air/heating/cooling delivery relative to ductwork configurations and effective flow rates.

- Evaluate ductwork-modeling software.

- Develop high-performance/NZ design and installation criteria for ductwork modeling and for onsite fabrication of ducts and distribution systems.

- Analyze and deconflict competing definitions of factors that constitute duct leaks versus envelope infiltration.

- Establish the overall performance effectiveness of central air distribution systems.

- Develop an updated method of test for the performance rating of heat pumps and central air conditioners to account for the operating schedule that is likely to occur in a NZE building.

- Develop a method of test for performance rating integrated heat pumps.

\subsubsection{Support for Alternate Conditioning Systems}

The NZRETF supports four alternate distinct heating/cooling systems - central air with high wall distribution, central air with floor distribution, 2-1 ducted mini-split HP system, and highvelocity cooling. In addition, the central air handler and distribution system is designed to accept a stand-alone dehumidification system.

Support for a standalone dehumidifier is integrated into the existing central air distribution system. As designed, this system could be used with a cooling/heating system that did not provide supplemental dehumidification, or it could be used in conjunction with a heating/cooling with dehumidification system for specific conditions or for evaluating conditioning performance. The ductwork for the standalone dehumidifier takes intake air from the living room at $255 \mathrm{~m}^{3} / \mathrm{h}$ $(150 \mathrm{cfm})$ and delivers the dehumidified air into the main supply trunk to be distributed to the living areas using the central air supply distribution system. The standalone dehumidifier is only permitted to operate when the heat pump system is not running.

As designed, the necessary ductwork and distribution system is installed for a second heat pump system. This 2-to-1 mini-split heat pump system has an external compressor unit and two ducted air handlers with independent controls that can be used in evaluating alternate/supplemental heating/cooling systems. The ductwork design includes a $2^{\text {nd }}$ floor air handler and ductwork in the attic; the $1^{\text {st }}$ floor air handler is to be concealed in the $1^{\text {st }}$ floor laundry closet with ductwork in the space between the first and second floors.

In addition, the NZERTF has installed a high-velocity cooling air distribution system to be used with a central space conditioning system. This small-diameter high-velocity air ductwork 
provides a second type of ductwork design to test for efficiency and indoor environmental quality (e.g., noise, air movement, occupant comfort).

\section{Research and Development Opportunities - Alternative Conditioning Systems}

- Evaluate the energy performance and thermal comfort of the duplicate system of supply run-outs from the supply air trunk designed using floor diffusers rather than wall/ceiling diffusers and for the kitchen, the ceiling diffuser.

- Evaluate the performance for switching between high wall and floor air distribution systems and/or to implement zone temperature control using the motorized isolation dampers installed in the ductwork.

- Test the performance of high- and low-velocity distribution systems for overall effectiveness:

- Evaluate effects on energy usage, thermal comfort, IAQ.

$\bigcirc$ Evaluate effects of zoning techniques and thermostatic controls.

○ Identify potential indoor environmental quality (IEQ) issues, e.g., noise/comfort levels, contaminant/particulate, volatile organic compounds (VOC) removal/release, and dust or mold issues.

- Investigate the optimization of ductwork selection (e.g., large vs. small high-velocity ducts) for different applications/designs/home configurations:

○ For both ducted systems, determine how installation details affect performance and which installation issues are most critical - sealing, design, sizing, or placement.

- Evaluate effects of smaller capacity central air systems on airflow rates and system design/sizing.

- Evaluate overall energy performance of the facility using the central air system in conjunction with stand-alone dehumidification and/or a mini-split heat pump system.

- Investigate energy performance and indoor environmental quality of stand-alone dehumidification technologies for Climate Zone 4A. Estimate humidity control and performance outcomes for other climate zones.

- Investigate the performance of mini-split heat pump as an alternate/supplemental heating/cooling system:

$\circ$ Evaluate dehumidification capabilities of mini-split heat pumps and their capacity to remove latent loads for dehumidification.

- Evaluate delivered performance and IEQ factors using the high-velocity air distribution system.

- Evaluate sorptive-based dehumidification systems for humidity control.

\subsubsection{Heat Recovery Ventilator System}

A mechanical ventilation system is used to provide the required outdoor air needed for a healthy indoor environment. The basic design of the ventilation system is an independently ducted, energy efficient, balanced residential ventilation system capable of meeting the American Society of Heating, Refrigerating and Air-Conditioning Engineers (ASHRAE) Standard 62.2- 
2010 ventilation rate required for the house. To address the energy efficiency requirement, heat recovery between the exhaust and the supply air streams was specified in the design. Also, the ventilation design incorporated the bathroom exhaust into the whole house ventilation system thereby reducing the number of penetrations through the enclosure and the number of fans required. This requirement was made primarily for the improved airtightness of the structure.

A fully ducted heat recovery ventilation system rather than an energy recovery ventilation (ERV) system was specified. Since an ERV system exchanges both heat and moisture between the exhaust and supply air streams, it is not appropriate for use when the exhaust air for the system is taken from the bathrooms where the moisture level is elevated.

The requirements specified for the HRV included the following:

- ECM motor(s);

- An operational capacity of the system of at least $255 \mathrm{~m}^{3} / \mathrm{h}(150 \mathrm{cfm})$ with $100 \mathrm{~Pa}(0.4$ in.w.g.) static pressure;

- Support for multiple speeds;

- Remote "boost" control mechanism for use in the bathrooms.

The air distribution for the ventilation system takes exhaust air from each of the three bathrooms and provides supply air to each of the second floor bedrooms and to the dining area. The HRV ductwork design called for individual ducts from the bathrooms joining a common return trunk in the basement running to the HRV. The supply distribution HRV ductwork design consisted of a common supply trunk that branched in the basement between the dining area and a common riser for the second floor bedrooms; the common bedroom duct branched into run-outs at the $2^{\text {nd }}$ floor level. While the capacity of the installed ventilation system $\left(180 \mathrm{~m}^{3} / \mathrm{h}(106 \mathrm{cfm})\right)$ is lower than designed $\left(255 \mathrm{~m}^{3} / \mathrm{h}(150 \mathrm{cfm})\right)$, it complies with the ventilation capacity requirements of ASHRAE 62.2-2010. The rated power consumption and effectiveness of the HRV are $54 \mathrm{~W}$ and 0.78 , respectively.

The ASHRAE 62.2-2010 ventilation requirements for the house are as follows:

- Bathroom ventilation - for each bathroom, $85 \mathrm{~m}^{3} / \mathrm{h}(50 \mathrm{cfm})$ for intermittent use or 34 $\mathrm{m}^{3} / \mathrm{h}(20 \mathrm{cfm})$ for continuous ventilation;

- For whole house ventilation $-137 \mathrm{~m}^{3} / \mathrm{h}(80 \mathrm{cfm})$.

\section{Research and Development Opportunities - Ventilation Systems and ASHRAE 62.2-2010}

- Evaluate ventilation requirements specified by ASHRAE 62.2-2010:

- Determine ventilation rates based on the building design and loads to achieve IAQ requirements.

- Determine whether the HRV functionally performs as predicted.

- Determine the total energy cost for continuous ventilation using required air exchange rates including HRV, dehumidification, and heating/cooling.

- Calculate or estimate equivalent energy costs for other climatic zones - e.g., hot humid and/or cold climate zones. 
- Determine and evaluate HRV ventilation flow rates that account for revisions in the code and "credits" awarded for infiltration rates.

- Instrument, measure, and baseline conditioned spaces for various IEQ criteria using ASHRAE 62.2-2010 ventilation requirement: (See also Section 4.0 Indoor Environmental Quality)

- Identify changes in the levels of outside pollutants entering enclosure.

$\circ$ Evaluate IAQ and other trade-offs to aggressive building ventilation approaches.

- Verify impact of various ventilation rates on emissions.

- Evaluate whether mechanical ventilation is the most effective method for indoor pollutant, odor, and particulate removal.

- Evaluate energy and IEQ/IAQ performance of straight/direct ventilation versus ERV or HRV while meeting requirements of ASHRAE 62.2-2010.

○ Evaluate an ERV system, its performance meeting ASHRAE 62.2-2010 requirements, and its impact on indoor humidity levels/control.

- Evaluate lifecycle cost (LCC) and overall energy performance of residential demandcontrol ventilation systems for meeting ASHRAE 62.2-2010 ventilation requirements.

\section{Research and Development Opportunities - Ventilation System and IEQ}

- Identify and evaluate alternative ventilation schemes for residential buildings.

- Determine minimum ventilation rates required to meet IAQ/IEQ performance criteria for a tight NZE enclosure.

- Evaluate other mechanical and passive ventilation approaches and technologies.

- Instrument each room and measure IAQ for odor/stagnant air and latent loads using different ventilation equipment/configurations/schemes:

$\circ$ Investigate and document HRV rates and schedules for energy performance when combined with on-demand ventilation and alternative/stand-alone systems for air circulation (fans) and odor removal (filters).

- Examine how energy use by mechanical ventilation technologies is affected by building type, and ventilation approach, and air exchange rates.

- Specify environmental/climate conditions under which mechanical ventilation systems will represent a significant factor in the overall energy performance for a NZ residential building.

- Examine and document the extent of interplay between the HRV and other appliances and their whole building effect and/or IAQ impact:

$\circ$ Quantify the IEQ impacts of direct ventilations systems - e.g., continuous operation of bathroom fans used in conjunction with a HRV and a makeup air system.

○ Measure impact of controlled leaks (e.g., actuating doors, windows, exhaust fans) on overall performance.

- Determine ventilation techniques that can be used to reduce thermal gradients. 


\subsubsection{Other Ventilation Systems}

This section describes additional mechanical ventilation systems that are installed and in operation in the NZERTF. As mentioned earlier, the ventilation design incorporated the bathroom exhaust into the whole house ventilation system thereby reducing the number of penetrations through the enclosure and the number of fans required.

\section{Kitchen Exhaust}

A range hood exhausting to the exterior is used for removal of cooking-related moisture, odors, and pollutants. The range hood is located over a $762 \mathrm{~mm}$ (30 in) induction cooktop. The Home Ventilating Institute (HVI) recommends $170 \mathrm{~m}^{3} / \mathrm{h}(100 \mathrm{cfm})$ of ventilation per lineal foot of cooktop for wall-mounted hoods, resulting in a $425 \mathrm{~m}^{3} / \mathrm{h}(250 \mathrm{cfm})$ exhaust rate to meet the HVI recommendations. ${ }^{14}$ The cooktop and range hood products selected for the NZERTF were from the same manufacturer. The smallest internal, in-line blower available for the range hood, a 510 $\mathrm{m}^{3} / \mathrm{h}(300 \mathrm{cfm})$ fan, was installed with the air exhausted to the exterior on the north side of the house. After installation, the exhaust rate for the range hood at the exterior outlet measured 260 $\mathrm{m}^{3} / \mathrm{h}(153 \mathrm{cfm})$ at the high-speed setting; for the medium-speed setting, the exhaust rate delivered $170 \mathrm{~m}^{3} / \mathrm{h}(100 \mathrm{cfm})$ meeting ASHRAE 62.2-2010 requirements.

\section{Make-up Air System}

Based on the extraordinarily airtight results of the first blower door test, BSC recommended that a make-up air system be installed to prevent depressurization of the house when the kitchen exhaust and/or the clothes dryer are operating. The principle of the makeup air system is that it be closed when no exhaust device (kitchen exhaust or clothes dryer) is operating, but open when an exhaust device is operating and the pressure differential between the interior and exterior is greater than $10 \mathrm{~Pa}$. The kitchen exhaust is programmed to operate at medium speed whenever the cooktop is used.

The design of the system consists of a $203 \mathrm{~mm}$ ( 8 in) round duct penetration through the attic wall on the west side of the house with a normally-closed, spring-return motorized damper that opens when the kitchen exhaust and/or the clothes dryer is operating. To the interior side of the motorized damper, a barometric damper is installed which begins to open when there is a pressure differential of $10 \mathrm{~Pa}$. The air that enters the attic through the $203 \mathrm{~mm}$ ( 8 in) make-up air duct will be tempered as it moves through the attic space and down into the living area.

\footnotetext{
${ }^{14} \mathrm{http} / / /$ www.hvi.org/publications/HowMuchVent.cfm
} 


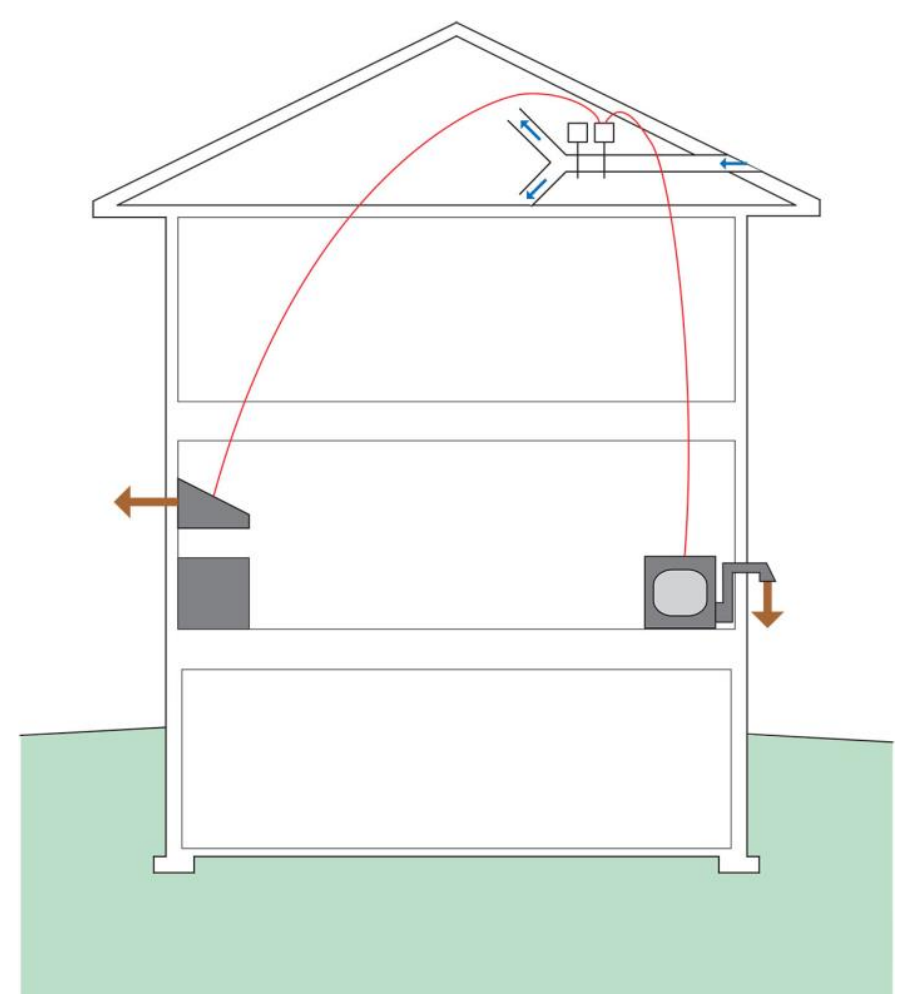

Figure 5: Schematic of Make-up Air System

\section{Research and Development Opportunities - Other Ventilation Systems}

- Evaluate the energy cost for unconditioned make-up air as a component to the cost/benefit analysis for high-performance tight building enclosures:

- Examine alternative methods for delivery of make-up air for dryers and kitchen exhaust hoods for houses with various levels of air infiltration.

- Quantify and evaluate the energy cost for make-up air required to accommodate combustible fuel appliances (e.g., NG/propane cooktops, heating appliances, fireplaces) and the cost benefit analysis for these alternative appliances.

- Examine the performance of kitchen exhaust and effectiveness of hood capture.

- Investigate an intelligent control system to operate the makeup air system and the bathroom exhaust fans to achieve required airflow/ventilation requirements.

\subsubsection{Geothermal Heating Systems}

The performance of geothermal heating systems can be measured and evaluated in the future using three independent ground source heat exchangers (GSHX) installed on the site. The three different configurations of geothermal loops were installed to the south, to the northwest and to the north of the house and capped for future use. A manifold system allows researchers to selectively activate which loop is coupled to the ground source heat pump (GSHP) and the thermal collection system. 


\section{Ground Source Heat Exchangers}

Three different systems of ground-source heat exchangers were installed in the immediate proximity of the NZERTF: 1) vertical borehole 2) horizontal u-tube, and 3) horizontal slinky (see Appendix C: Figure 10). Each GSHX is independent and has been sized to meet the heating and cooling loads of the NZERTF when used in conjunction with an appropriately sized GSHP. The construction of each GSHX is similar, with the exception of the geometric orientation and length of the main heat exchanger tubing within the trenches/boreholes. The tubing for all three heat exchangers consists of High Density Polyethylene (HDPE) plastic. The nominal inside diameter of the tubing is $2.54 \mathrm{~cm}(1.0 \mathrm{in})$ for the actual heat exchangers and $3.81 \mathrm{~cm}(1.5 \mathrm{in})$ for the supply and return lines. Each of the three GSHX has three parallel legs that are coupled together outside the structure by a switchable manifold (see Appendix C: Figure 10).

Overall heat transfer can be characterized using the mass flow rate and supply/return temperature measurements. Resistance temperature detector (RTD) sensor devices buried with the HDPE tubing in the trenches are used to characterize local heat transfer between the tubing and surrounding earth and attached to the tubing and insulated to measure the internal fluid temperature.

\section{Research and Development Opportunities - Ground Source Heat Exchangers}

- Perform short-term characterization to quantify thermal performance of the GSHX loops:

- Measure and quantify overall heat transfer rates using the mass flow rate and supply/return temperature measurements for each GSHX loop.

- Characterize heat transfer rates for the overall system and individual loop segments.

- Characterize the longer-term soil conditioning period and performance of each GSHX loop:

- Examine rate of flows and energy capacity for each loop configuration.

- Quantify the heat load generated inside the conditioned space of the NZERTF as the result of using an artificial device to provide defined thermal loads on the GSHX loops.

- Install and evaluate the performance of a fourth geothermal loop design based upon large

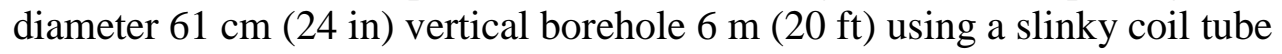
configuration. Document the total cost of materials and installation and the annual heat transfer performance of the heat exchange loop.

- Measure in situ performance of the ground source heat pump using the temperature differential and flow rate. Extend the analysis to the collection and distribution system.

\section{Ground Source Heat Pumps}

For the initial design and during the first year demonstration phase, the NZERTF did not include a GSHP unit integrated with the installed GSHX systems. Future research on ground source heating systems will require specification and installation of the appropriately sized heat pump for the NZERTF. 


\section{Research and Development Opportunities - Geothermal Heat Pump Systems}

- Evaluate a smart geothermal design that integrates a variable speed compressor and smart thermostat using electrical grid price signals or user intervention (e.g., using a smart device) to modulate energy load.

- Evaluate a hybrid ground-coupled heat pump system that integrates solar thermal collectors to supplement heat extraction during the heating season.

- Determine feasibility and document performance of using the ground source HP for domestic hot water production based upon demand response and daily hot water consumption rates.

\subsubsection{Hydronic Radiant Floor Heating System}

The basement slab of the NZERTF incorporates a 9-circuit radiant floor heating system. The radiant floor tubing is placed $20.3 \mathrm{~cm}$ (8.0 in) apart with a maximum circuit length of $76 \mathrm{~m}$ (250 $\mathrm{ft}$ ). The basement floor construction consists of a filter fabric laying on undisturbed soil, $10.2 \mathrm{~cm}$ (4.0 in) of stone, $5.1 \mathrm{~cm}$ (2.0 in) of extruded polystyrene insulation, a $0.15 \mathrm{~mm}$ (.006 in) polyethylene vapor barrier, and finally the $10.1 \mathrm{~cm}$ (4.0 in) concrete slab with the embedded radiant floor tubing. The supply and return manifolds are accessible to permit the selection of individual or various combinations of the fluid circuits for future studies.

\section{Research and Development Opportunities - Radiant Floor Heating System}

- Investigate the performance of the hydronic radiant floor heating system:

- Examine rate of flows and response rates for alternate fluid circuit designs.

$\circ$ Characterize the thermal energy storage capacity and response rates for insulated concrete slabs.

- Evaluate the thermal comfort for the basement area based upon radiant floor heating and combined radiant floor heating and central air space conditioning.

\subsection{Hot Water Systems}

The domestic hot water system for the NZERTF consists of a solar water heating system combined with a backup air-to-water HP and storage tank. The hot water supply manifold and a similar cold-water manifold distribute water directly to each fixture, toilet, and water-utilizing appliance in the home through $9.5 \mathrm{~mm}$ (3/8 in) cross-linked polyethylene (PEX) tubing. The entire length of tubing carrying hot water to each end-use is insulated. The dishwasher uses hot water, exclusively. The fixtures were manually adjusted to provide a mixed water temperature of approximately $41^{\circ} \mathrm{C}\left(106^{\circ} \mathrm{F}\right)$ at the sinks and showers, and $43{ }^{\circ} \mathrm{C}\left(110^{\circ} \mathrm{F}\right)$ at the bathtubs. ${ }^{15}$ Plumbing fixtures were specified as low flow and WaterSense ${ }^{\circledR}$ fixtures.

\subsubsection{Solar Hot Water Heating Systems}

The residential test facility is equipped with two active, closed-loop solar water heating systems. The four flat plate solar thermal collectors (approximately $4.6 \mathrm{~m}^{2}$ or $50 \mathrm{ft}^{2}$ total surface area) are

${ }^{15}$ ASHRAE, Table 3 Representative Hot-Water Temperatures, Chapter 50: Service Water Heating, in 2011 ASHRAE Handbook - HVAC Applications, ASHRAE, Inc., Atlanta, GA, 2011. 
installed $14 \mathrm{~cm}$ (5.5 in) above the asphalt shingle roof surface of the uninsulated front porch assembly. During the first year of demonstration, only one of the two systems was operational and used to heat domestic hot water (DHW). The solar DHW system utilized two solar collectors, and a $303 \mathrm{~L}$ (80 gal) storage tank with its integrated $4500 \mathrm{~W}$ auxiliary heating element disabled, (see Figure 6). The second system, which uses two separate solar collectors and utilizes a $454 \mathrm{~L}$ (120 gal) storage tank, will be used in future research in combination with the basement floor radiant heating system and/or the ground source heat pump system.

The solar collectors, heat exchangers, circulators, and controls are identical for both systems. Each solar thermal collector array consists of two SRCC OG- $100^{16}$ certified single-glazed flat

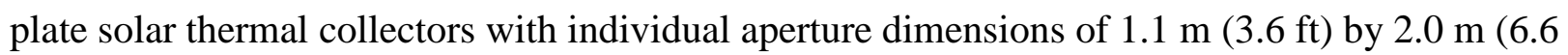
$\mathrm{ft})$. The collectors are located on the porch roof, facing true south at an $18.4^{\circ}$ tilt. To prevent freezing, a 50 percent by volume propylene glycol in water solution is used in the collector fluid lines.

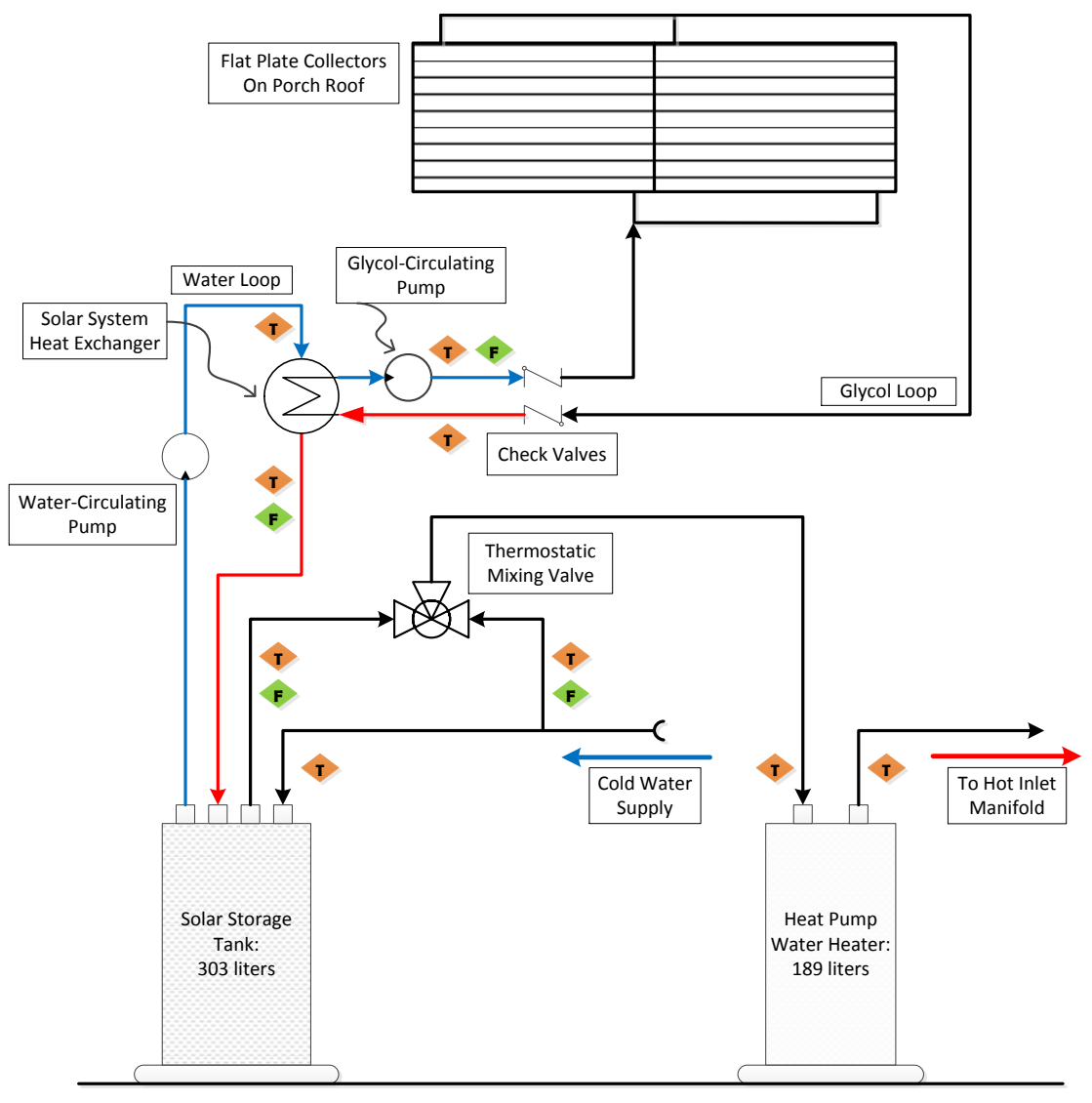

Figure 6: Schematic of Solar Thermal and Heat Pump Water Heater

\footnotetext{
${ }^{16}$ SRCC ${ }^{\text {TM }}$ Standard 100: Minimum Standards for Solar Thermal Collectors @2012 Solar Rating \& Certification Corporation $^{\mathrm{TM}}\left(\mathrm{SRCC}^{\mathrm{TM}}\right)$.
} 
During the first-year demonstration phase, the solar thermal system provided 54 percent of the energy required to meet the domestic hot water load.

\section{Research and Development Opportunities - Solar Water Heating Systems}

- Investigate the energy impact of using a lower viscosity corn glycol in place of propylene glycol for the circulation fluid for the solar thermal collectors.

- Investigate combined solar/geothermal heat pump systems (see Section 3.2.7 Geothermal Heating Systems).

- Compare the relative economic tradeoffs of a larger photovoltaic system in lieu of a solar photovoltaic system in combination with a solar thermal hot water system.

- Compare the performance of a solar hot water system using conventional circulating pumps versus photovoltaic-driven direct current pumps.

- Establish measurement science, appropriate methods of test, metrics, and protocols to accurately quantify performance of solar thermal panels, water distribution systems, and energy storage systems.

- Evaluate energy storage technologies/materials, identify technologies that are effective, and perform data collection on the in situ performance of these technologies:

$\circ$ Investigate performance on diurnal and seasonal bases in response to varying load types.

Investigate how seasonal performance differences and storage capacity affect the annual NZE performance capability.

\subsubsection{Auxiliary Heat Pump Water Heating System}

The solar hot water heating system has a backup system to ensure that hot water is available at all times. For the demonstration phase, the design called for an air-to-water heat pump system used for supplemental heat to be integrated downstream from the solar hot water heating system. The mean temperature to be maintained by the full system is $49^{\circ} \mathrm{C}\left(120^{\circ} \mathrm{F}\right)$. The requirements specified for the backup heat pump water heater included the following:

- Energy Star qualified;

- 189 L (50 gallon) storage tank;

- Energy factor of 2.0 or greater;

- Electric element backup with maximum input power of $4.5 \mathrm{~kW}$.

Downstream of the solar hot water system, a heat pump water heater provides domestic hot water in the event that the solar thermal water heating system cannot meet demand. The unit consists of a $189 \mathrm{~L}$ (50 gal) storage tank with an integrated heat pump water heater. The system is operated in the "Hybrid" mode with a temperature setpoint of $49^{\circ} \mathrm{C}\left(120^{\circ} \mathrm{F}\right)$. The "Hybrid" mode ensures that the heat pump provide a majority of the hot water load while energizing the $3800 \mathrm{~W}$ electric element only when the heat pump cannot meet the hot water demand. In the "Hybrid" mode with a setpoint temperature of $57^{\circ} \mathrm{C}\left(135^{\circ} \mathrm{F}\right)$ and an ambient temperature of $20^{\circ} \mathrm{C}\left(68^{\circ} \mathrm{F}\right)$, the 
manufacturer-reported Energy Factor (EF), Coefficient of Performance (COP) and standby loss of the unit are $2.5,2.6$, and $0.20^{\circ} \mathrm{C} /$ hour $\left(4.5,4.7\right.$, and $0.36^{\circ} \mathrm{F} /$ hour $)$, respectively.

During the first-year demonstration phase, the auxiliary water heating system delivered $1563 \mathrm{kWh}$ of thermal energy while consuming a total of $1112 \mathrm{kWh}$ including $137 \mathrm{kWh}$ for resistance heat.

\section{Research and Development Opportunities - Domestic Hot Water Systems}

- Investigate the in situ performance of the domestic hot water system components.

$\circ$ Investigate secondary sources for the variation in predicted total water heating energy consumption with actual first year energy consumption beyond solar insolation effects.

- Investigate heat loss sources that compromise effective onsite energy production and delivery.

- Evaluate the impact of HP water heating systems on space conditioning loads.

- Investigate predicted and in situ performance of combined domestic hot water and central heating geothermal heat pump configurations (see also Section 3.2.7 Geothermal Heating Systems).

- Develop the measurement science with appropriate methods of test, metrics, and protocols to characterize performance of thermal energy storage devices.

- Investigate the use of heat exchange from greywater sources to reduce water-heating load.

- Determine the in situ Energy Factor, Coefficient of Performance (COP) and standby loss of the unit with setpoint of $49^{\circ} \mathrm{C}\left(120^{\circ} \mathrm{F}\right)$ using seasonal ambient basement temperatures.

\subsection{Water Fixtures and Appliances}

The average daily water consumption for showers (123.7 L/day, [32.7 gal/day]), baths (31.0 L/day, [8.2 gal/day]), and sinks (110.3 L/day, [29.1 gal/day]) for the virtual family was established based upon three domestic hot water studies. ${ }^{17}$ Thus the average total daily water usage is $265 \mathrm{~L}$ ( $70 \mathrm{gal}$ ) not including the water consumption by the dishwasher and the clothes washer. During each of the 44 daily scheduled water draws, and any weekly scheduled clothes washer or dishwasher events, water temperatures and flow rates are recorded every 3 seconds.

\subsubsection{Water Fixtures}

To support efficient distribution of the hot water, the design specified a central PEX manifold system with insulated $9.5 \mathrm{~mm}$ (3/8 in) supply lines to the fixtures. With all fixtures located in the same quadrant of the house as the manifold, supply runs are of minimal length. With the exception of the hose bibs, no plumbing lines are located in the exterior walls. See also Section 8 Water Appliances and On-Site Water Collection Systems.

\footnotetext{
${ }^{17}$ Ibid.
} 
Low flow and WaterSense ${ }^{\circledR}$ fixtures were specified as follows:

- All lavatory faucets to be WaterSense ${ }^{\circledR}$ certified and flow rate of $5.7 \mathrm{~L} / \mathrm{m}(1.5 \mathrm{gpm})$ or less;

- Kitchen faucet to have flow rate of $8.3 \mathrm{~L} / \mathrm{m}(2.2 \mathrm{gpm})$ or less;

- All shower fixtures to have flow rate of $6.6 \mathrm{~L} / \mathrm{m}(1.75 \mathrm{gpm})$ or less;

- All toilets to have a water usage of $3.8 \mathrm{~L} / \mathrm{f}(1.1 \mathrm{gpf})$ or less.

\section{Research and Development Opportunities - Plumbing Fixtures}

- Investigate energy and water performance of $75.7 \mathrm{~L}$ (20 gal) capacity water recycling systems for bathroom showers using filtered, and reheated water.

- Evaluate pressure drop and water delivery performance of PEX distribution system.

- Develop metrics for energy losses in distribution systems and compare performance to other types of water distribution systems.

- Assess water losses and time delays in delivering usable hot water to an end fixture accounting for the manifold system, distribution system design, and clustered locations of water end-uses; compare to other plumbing designs with and without insulation.

- Develop the statistical properties of the water distribution system efficiency based on a variety of draw patterns that may be observed in a home.

- Assess durability of PEX distribution systems.

\subsubsection{Standard Water Home Appliances}

Typical water appliances in the NZERTF beyond plumbing fixtures include the dishwasher (hot water only) and clothes washer (hot and cold water). Both are Energy Star qualified appliances for energy consumption. During the weekly scheduled clothes washer or dishwasher events, water temperatures and flow rates are recorded every 3 seconds. The number of cycles per week, for the dishwasher, clothes washer, and the clothes dryer is based on a survey conducted by Proctor and Gamble. ${ }^{18}$ Research on these and other water-efficient appliances can be performed in the NZERTF.

\section{Research and Development Opportunities - Plumbing Fixtures}

- Compare water and energy performance of dishwasher and clothes washer over time to rated values.

\subsection{Electrical Systems}

The NZERTF uses two independent electrical distribution systems. The first system powers the electrical loads that would normally exist in a residence. The second electrical system powers research apparatus - loads that would not be present in a typical residence, including the dedicated heating/cooling system in the detached garage, the instrumentation used to monitor the

\footnotetext{
${ }^{18}$ C. Iglehart, N. Milesi-Ferretti, and M. Galler, Consumer Use of Dishwashers, Clothes Washers, and Dryers : Data Needs and Availability, NIST Technical Note 1696 (2011).
} 
facility, and the devices used to simulate occupant sensible and latent heat loads. Separating these two electrical systems allows one residential-style smart meter to directly measure electrical energy production and consumption, and to verify on an annual basis, that the NZERTF achieves or exceeds its net-zero energy goals.

The smart meter registers the electrical energy imported from and exported to the grid on a fifteen-minute basis. For more detailed measurements of energy consumption and generation within the house each circuit breaker is equipped with a power meter that captures the instantaneous power and cumulative energy use. The layout of each electrical circuit was carefully planned so that the electrical use of individual devices, such as the heating/cooling systems, lights, appliances, plug loads, and the sensible and latent loads of the virtual occupants, could be measured independently. Individual circuits are dedicated to the heat pump, HRV, solar hot water system, and HP domestic hot water system.

\subsubsection{Lighting and Fan Design}

The lighting plan for the NZERTF provides an overhead light and switched outlets for plug-in lamps for each room except for the kitchen and the living room. Halls, closets, and the basement have overhead lighting only. Bathrooms use special task lighting. The living room uses dimmable downlights for overhead lighting with accent lighting as well as switched outlets for plug-in lamps. The kitchen has more built-in lighting - both overhead light and task lighting than the other parts of the house.

The Energy Star lighting fixtures use only light-emitting diode (LED) or pin-based compact fluorescent lamps (CFL). The design for fixtures and lamps used the following criteria:

- Downlights: LED with minimum 500 lumens for $102 \mathrm{~mm}$ (4 in) apertures and 650 lumens for $152 \mathrm{~mm}$ (6 in) apertures, maximum $11 \mathrm{~W}$;

- Under cabinet lights: LED with minimum 180 lumens, maximum $6 \mathrm{~W}$;

- Compact fluorescent lights: at least 60 lumens/W;

- Lighting quality: color rendering index (CRI) minimum 90, correlated color temperature (CCT) $2700 \mathrm{~K}$ to $3000 \mathrm{~K}$.

All of the kitchen fixtures were specified to use LED lamps. The kitchen ambient lighting consisted of three downlights located over the counters (457 mm or 18 in from the wall). A photo sensor controlled by the daylight level and a manually controlled dimmer are provided for the ambient lighting. Separate switches were provided for each of the following:

- Single down light over kitchen sink;

- Under cabinet lights on west wall;

- Under cabinet lights on north wall;

- Downlights over kitchen peninsula.

The switches located at the entrances to the kitchen are for ambient lighting only so that the remaining kitchen lighting will be turned on as needed for specific tasks. The lighting in the 
living room uses separate switching as well - one for the ambient down lights and one for the accent lights - with a dimmer for the ambient lighting.

The facility has wiring installed for ceiling fans in the bedrooms and living room for use in future IEQ research. While no ceiling fans are currently installed, the designed performance specifications for energy consumption and air moving performance of the ceiling fans is specified as follows: ${ }^{19}$

- Low: $12.5 \mathrm{~W}$ for $4120 \mathrm{~m}^{3} / \mathrm{h}(2425 \mathrm{cfm})$ or $330 \mathrm{~m}^{3} / \mathrm{h}$ per W $(194 \mathrm{cfm} / \mathrm{W})$;

- Medium: $25.6 \mathrm{~W}$ for $6485 \mathrm{~m}^{3} / \mathrm{h}$ or $253 \mathrm{~m}^{3} / \mathrm{h}$ per watt $(149 \mathrm{cfm} / \mathrm{W})$;

- High: $53.3 \mathrm{~W}$ for $10367 \mathrm{~m}^{3} / \mathrm{h}$ or $194 \mathrm{~m}^{3} / \mathrm{h}$ per watt $(114 \mathrm{cfm} / \mathrm{W})$.

\section{Research and Development Opportunities - Lighting and Fan Systems}

- Install and evaluate the effectiveness of ceiling fans to improve IAQ and inhibit air stratification and thermal gradients in combination with the central air ventilation system.

- Evaluate performance and lifecycle cost of automated dimming for ambient lights based on daylight level:

$\bigcirc$ Evaluate the energy benefit/penalty for lighting control devices used by highefficiency LED lighting including power conversion and communications for automated lighting controls.

- Investigate issues related to proprietary communications protocols, controllers, and transformers used in automated lighting control in the residential setting.

- Evaluate feasibility, cost/benefit, and performance of direct current (DC) electrical distribution to lighting fixtures, computers, and other plug loads from renewable PV energy collection and storage devices.

\subsubsection{Standard Electrical Home Appliances}

The types of appliances included in the NZERTF are typical for a new house of this size and locale. The size and features specified for the appliances is a combination of what is typically expected for a family of four and what devices are of particular interest to the NIST researchers. The specifications for each type of appliance were based on the most efficient Energy Star appliances that were available at the time of purchase with the desired size and features. ${ }^{20} \mathrm{Grid}$ connected or grid-aware appliances (aka "Smart Appliances") were not available when the appliances were procured.

\section{Research and Development Opportunities - Standard Electrical Home Appliances}

- Investigate the full range of research topics associated with grid-connected appliances (see also Section 6.1 Intelligent System Control) and associated demand-response capabilities:

\footnotetext{
${ }^{19}$ Based on efficiency of Energy Star ceiling fans available at gossamerwind.com

${ }^{20}$ Building Science Corporation, "Net Zero Residential Test Facility Specifications", March 30, 2010.
} 
- Collaborate with industry, non-governmental organizations, and federal agencies on communication standards and protocols for appliance/grid interactions.

- Identify and evaluate building control systems to coordinate appliance interactions and to transact with utilities on demand response and pricing signals from the electrical grid.

- Evaluate demand response strategies for residential appliances

○ Develop test methods/performance metrics for innovative and combined appliances

- Investigate the design and performance of energy capture alternatives for heating purposes (e.g., domestic hot water) and micro combined heat and power (micro-CHP) technologies:

○ Evaluate feasibility of residential "transaction energy" - generating or selling energy back to the utility during high price periods - for micro-CHP.

- Evaluate feasibility and performance of combustible fuel appliances (e.g., NG cooktops, heating appliances, fireplaces) in high-performance NZE enclosures.

- Investigate efficient appliance/equipment interaction and response to electrical grid pricing signals with respect to response type, and appliance vs. whole building control (see also Section 6.1 Intelligent System Control).

- Investigate simplified product certification methods that limit duplicative and/or costly testing of individual appliances and of systems of devices.

- Investigate new methods of test that would allow installed performance to be captured versus laboratory-based testing and evaluation.

\subsubsection{Solar Photovoltaic System}

To meet the projected energy consumption, the final design specified thirty-two $320 \mathrm{~W}$ panels mounted at an $18.4^{\circ}$ tilt (roof slope of 4:12) for a $10.24 \mathrm{~kW}$ system with a predicted output of $14800 \mathrm{kWh} /$ year. $^{21}$ The modules are interconnected to form four parallel strings of eight seriesconnected modules. The power, voltage, and current at maximum power for the array at Standard Test Conditions (STC) ${ }^{22}$ are $10.24 \mathrm{~kW}, 438 \mathrm{~V}$, and $23.4 \mathrm{~A}$, respectively. The panels are mounted approximately $14 \mathrm{~cm}$ (5.5 in) above the fully exposed asphalt surface of the shed dormer on the front of the house.

The south-facing roof of the detached garage, located to the west side of the house, provides additional space for solar panels. For the demonstration phase, the garage roof was not to be used for photovoltaic panels but should additional or alternative solar panels be needed for research purposes, the 9.5:12 sloped garage roof is suitable for use.

\footnotetext{
${ }^{21}$ Ueno, K., Memo: NIST NZERTF Zero Energy Performance, October 28, 2009.

22 IEC Standard 61215, Crystalline silicon terrestrial photovoltaic (PV) modules - Design qualification and type approval, International Electrotechnical Commission (IEC), Geneva, Switzerland (2005).
} 


\section{Research and Development Opportunities - Photovoltaic Systems}

- Investigate energy storage technologies including electric vehicles (EV) and other storage technologies linked directly to PV array system:

○ Identify and investigate environmentally sustainable and economical methods for residential energy storage such as flywheel and hydrogen fuel cells.

- Model effects of storage on overall NZE performance independent of renewable technologies used. Quantify savings or potential to lower total energy costs.

- Investigate decision support strategies for storing or selling generated energy based on grid pricing signals.

- Improve performance monitoring for control of energy systems:

- Investigate potential Smart Grid integration issues associated with the accuracy of forecast energy collection as compared with actual energy collection.

- Develop/improve test methods and predictive models to accurately estimate annual energy production of solar photovoltaic and solar thermal systems.

- Investigate shading/snow accumulation effects on PV collector performance:

○ Mitigate effects of snow loads on PV sensors and collectors.

- Investigate snow removal techniques (active) and potential PV installation/location changes (passive).

- Evaluate alternate photovoltaic technologies (e.g., PV shingles, pavers).

- Evaluate heat load transfer effects on the roof/attic system from roof-mounted PV collectors.

- Compare the in situ performance of photovoltaic systems using micro inverters to the use of central inverters in terms of durability and overall conversion efficiency.

\subsection{Indoor Environmental Quality}

Indoor environmental quality (IEQ) refers to the quality of a building's environment in relation to the health and wellbeing of those who occupy space within it. IEQ includes many factors, including lighting, air quality, acoustics, and damp conditions that promote bacteria or mold growth. While research has shown that some respiratory symptoms and illnesses can be associated with damp buildings, it is still unclear what measurements of indoor contaminants show that building occupants are at risk for disease ${ }^{23}$ Despite uncertainty about what to measure and how to interpret what is measured, research shows that building-related symptoms are associated with building characteristics, including dampness, cleanliness, and ventilation characteristics. ${ }^{24}$ Other factors include the location of the building, the building's uses and occupant behaviors (e.g., smoking or the use of hazardous chemicals), building materials, and other sources of harmful chemical emissions. The NZERTF provides a test venue to develop improved methods of test and metrics for IEQ and to evaluate the impacts on IEQ by highperformance building design and systems.

${ }^{23}$ Center for Disease Control (CDC). Indoor Environmental Quality. http://www.cdc.gov/niosh/topics/indoorenv/

${ }^{24}$ Ibid. 
Specific restrictions were provided by NIST during the design phase of the NZERTF for building products containing volatile organic compounds (VOC) and aldehydes. The restrictions applied to structural wood products, adhesives and sealants, interior wood-based products, interior paints and other coatings, interior-side insulation, cabinetry and wallboard used to the interior side of the airflow control system (air barrier membrane). These restrictions were stricter and more specific than recommendations contained in LEED for Homes ${ }^{25}$.

The interior building materials used in the NZERTF are documented to have low emissions of VOCs and include a prohibition on products with any added formaldehyde. Indoor air samples are collected to measure the levels of over thirty individual VOCs and formaldehydes in order to determine the impact of the NZERTF building material specifications. These samples are collected monthly and will be used to determine if the VOC emission rates for the house change over time. Measurements to date ${ }^{26}$ show that the use of medium density fiberboard and particleboard with no-added formaldehyde resins for cabinetry and other finished products effectively controlled the formaldehyde emissions and kept concentrations below levels typical in new homes.

Indoor air quality (IAQ) refers to the air quality within and around buildings and structures, and how it affects the health and comfort of building occupants. IAQ can be adversely affected by building materials and adhesives, furnishings, poor air circulation and ventilation, humidity, and outdoor sources of contaminants such as building or automobile exhaust emissions. Types of contaminants include carbon monoxide, radon, volatile organic compounds, particulates, and microbial contaminants such as mold and bacteria, as well as occupant-generated sources from smoking or use of cleaning fluids or perfumes. Source control, filtration, and the use of ventilation are the primary means to control contaminant levels and maintain a healthy indoor air quality.

\section{Research and Development Opportunities - Indoor Environmental Quality}

- Examine thermal comfort, IAQ, acoustic effects, and energy impact of mechanical ventilation (e.g., HRV) meeting ASHRAE 62.2-2010 airflow requirements and other ventilation schemes for residential space conditioning design:

- Determine IAQ/comfort issues that arise when space conditioning equipment doesn't properly account for low sensible loads, larger latent loads, and more infrequent operation of the central air distribution/HRV systems - e.g., stagnant air and thermal gradients.

- Quantify the IAQ impacts of direct exhaust systems - e.g., continuous operation of bathroom fans used in conjunction with the HRV and makeup air systems.

- Determine whether mechanical ventilation techniques can be effectively used to manage air stratification, odor elimination, and thermal gradients.

\footnotetext{
${ }^{25}$ Leadership in Energy and Environmental Design, U.S. Green Building Council, (2008).

${ }^{26}$ Poppendieck, D., Ng, L., Schlegel, M., Persily, A., Hodgson, A., "Long Term Air Quality Monitoring in a NetZero Energy Residential Test Facility Designed with Specifications for Low Emitting Interior Products",

Conference Proceedings of Indoor Air 2014, (2014).
} 
- Examine how different ventilation approaches/technologies impact volatile organic compound (VOC) concentrations and odor removal, e.g., exhaust-only systems with or without a makeup air system:

- Examine cost/benefits of using filtration as a possible trade-off for source control and ventilation air exchange rates.

- Examine performance of forced-air system filters for removal of noxious chemicals and particulates.

- Investigate low-cost, low-energy air cleansing systems:

- High capacity sorbent-based systems and low temperature catalysts for VOC removal.

- Sorbent-based systems for latent heat/humidity control.

- Energy requirements for active filtration systems relative to prescribed air ventilation rates.

- Compare and quantify differences in air contaminant measurement results acquired from discrete sampling approaches with analyzers that allow for continuous measurement of contaminant levels.

- Define key barriers to development of metrics for IAQ and comfort for residential buildings, based upon variability in occupant activities, product use, building design:

- Develop appropriate metrics for performance criteria given the interactions and effects across a broad range of drivers - energy, comfort, IAQ and health.

- Examine the impacts on IAQ based upon the type of ventilation used and the effects of positive and negative pressurization on the infiltration of VOCs/aldehydes in the NZERTF. (See also, Section 4.3 Radon)

- Examine how ventilation rates and their schedules impact VOC concentrations and whether ventilation requirements contained in ASHRAE Standard 62.2-2010 adequately limit (or acerbate) VOCs concentrations in a typical residential home:

- Estimate VOC concentrations for enclosures with higher levels of air infiltration with less stringent VOC limits on construction products, with and without mechanical ventilation.

- Estimate the impact of door and window operation, and other occupant activities, on ventilation rates and schedules and VOC concentrations.

- Evaluate new IAQ rules that focus on "equivalent occupant exposure" factors.

- Determine if there is any measurable effect in the operation of exhaust (bathroom and kitchen) fans in drawing VOC emissions into the living spaces from the building envelope components.

- Investigate passive contaminant removal technologies:

- Measure for the presence of ozone and confirm the effectiveness of clay-based paints and plasters for passive ozone removal.

- Examine indoor particulate levels and entry of outdoor particulates, such as those associated with the nearby interstate highway, given the uniqueness of the ventilation system (tight building envelope using a balanced mechanical ventilation system).

- Examine the impact of furniture and household products on VOC levels in the NZERTF. 
- Examine the effects of moisture/humidity on surface materials (e.g., carpets) for chemical changes to airborne contaminants and the production of harmful chemical by-products and reaction products.

- Measure the effects on VOC emissions of advanced fenestration (e.g., electrochromatic glass) that lowers surface temperatures of interior surfaces and furnishings.

- Monitor seasonal indoor VOC concentrations for evidence that building envelope components are a source for VOCs, especially aldehydes and alkanes. ${ }^{27}$

- Use high-definition system and environmental data to validate prior data/results produced at different locations/climate zones on effective ventilation rates and rules per ASHRAE 62.2-2010.

- Use high-definition IAQ measurements to determine settings for the ventilation system economizer to optimize the balance between energy cost and IAQ.

- Examine whether existing physical models of VOC emission rates are accurate and if concentrations change or stabilize over time as the materials age or go through seasonal temperature and humidity variations:

- Model and measure changes to VOC levels during periods of rapid cooling with increases in humidity resulting from the use of setback thermostats used during hot humid seasons.

- Model effects of solar radiation and humidity variations on increased VOC releases from fabrics, furniture, and flooring products.

- Verify IAQ monitoring approach — type and intensity — required to understand contaminant sources and how to structure mitigation strategies:

○ Determine which contaminants should be monitored and at what frequency.

- Determine analysis approaches for measured contaminant data to identify indoor contaminant sources.

○ Determine which IAQ metrics would be most useful for residential buildings.

\subsubsection{Radon}

Radon resistant construction practices were used in the NZERTF per local building code although due to measured levels of radon, active radon removal systems (i.e., fan driven) are not installed. Tests to measure indoor radon concentrations in the house used charcoal test kits following EPA Protocols for Radon and Radon Decay Product Measurements in Homes ${ }^{28}$. Radon measurements were made in the basement, first floor, and second floor. The average of all samples is below the EPA action level of $148 \mathrm{~Bq} / \mathrm{m}^{3}(4 \mathrm{pCi} / \mathrm{L})$. As a result, no active radon evacuation system is used though a perforated schedule 40 PVC pipe grid was installed below the slab to accommodate future experimentation of radon mitigation technologies.

\footnotetext{
27 Ibid.

28 "Protocols for Radon and Radon Decay Product Measurements in Homes", U. S. Environmental Protection Agency, Washington D. C., (1993).
} 


\section{Research and Development Opportunities - Radon}

- Test for potential air infiltration from the basement living area into the active radon evacuation system due to cracks or leaks in the slab/foundation system:

- Quantify the levels of infiltration and identify potential negative effects from the active radon evacuation system.

\subsection{Thermal Comfort}

Thermal comfort is a measure of an occupant's comfort level in his or her immediate surroundings. Factors affecting an occupant's thermal comfort include heat gain and loss, air temperature, mean radiant temperature, air flow/speed, and relative humidity. Installed within the NZERTF's kitchen, living room, and the three bedrooms are sensors for indoor bulb temperature, globe temperature, and relative humidity sensors. Measurements taken by these sensors are used to measure thermal comfort parameters defined in ANSI/ASHRAE Standard 552010: Thermal Environmental Conditions for Human Occupancy ${ }^{29}$.

Thermal comfort parameters Predicted Mean Vote (PMV) and Predicted Percentage of Dissatisfied (PPD) are used and values of PMV between -0.5 and +0.5 and PPD $<10$ are considered "comfortable." In the summer, the occupants are assumed to be clothed between 0.36 clo (walking shorts, t-shirt) and 0.57 clo (short-sleeve shirt, trousers), where "clo" is the clothing insulation level. In the winter, the occupants are assumed to be clothed between 0.61 clo (longsleeve shirt, trousers) and 1.14 clo (suit jacket, vest, long-sleeve shirt, trousers). It is assumed that the activity level of the occupants range between 0.7 met (sleeping) and 1.7 met (walking about), where "met" is the metabolic rate.

\section{Research and Development Opportunities - Thermal Comfort}

- Use NZERTF as a test bed to develop and evaluate methods of test for thermal comfort factors.

- Quantify and characterize environmental parameters and movements of heat/contaminant loads introduced into the controlled (tight) environment.

- Measure/visualize airflows using tracer gases to assess airflow and circulation and the effectiveness of the ventilation and distribution systems.

- Instrument rooms using towers of multiple sensors at different elevations to monitor effects of mechanical ventilation on indoor environmental quality including thermal comfort/gradients and the removal of stagnant air and odors.

- Evaluate the HRV performance and ASHRAE 62.2-2010 ventilation requirements and their combined impact on humidity, thermal gradients, and overall thermal comfort.

- Determine effects on thermal comfort from heat gain and loss, air temperature, mean radiant temperature, air flow/speed, and relative humidity in different room locations with different space-conditioning and air-distribution systems:

\footnotetext{
${ }^{29}$ American Society of Heating, Refrigerating and Air-Conditioning Engineers, Inc., Atlanta (2010).
} 
Determine key factors in the NZERTF design and their contributions to thermal comfort.

\subsection{Lighting and Acoustics}

Other IEQ factors that can be examined in the NZERTF include the quality of lighting and noise. Design factors affecting lighting include the number, size, and placement of exterior windows for daylighting. Other systems impacting the acoustics of the facility include the air distribution ductwork systems and other mechanical systems. Ambient noise levels are affected by the enclosure design and window systems.

\section{Research and Development Opportunities - Other IEQ: Lighting and Acoustics}

- Examine IEQ factors for acoustics and illumination and verify that the facility is able to meet IEQ performance requirements and achieve its intended function:

○ Examine acoustic effects from high-velocity air distribution system.

- Examine the uniformity of illumination for the task lighting areas.

- Measure the ambient noise levels and noise suppression performance for the NZERTF enclosure design.

\subsection{In Situ Performance}

The measured performance of individual building devices is traditionally performed: by an accredited laboratory; in a controlled environment and according to standardized and accepted industry standards and test procedures. ${ }^{30}$ In situ performance of a building, or building component or system measures the achieved performance as delivered when installed and connected to ancillary systems. The in situ performance of a component or system more accurately measures its achieved performance relative to its programmed mode of operation and the installed environment.

The extensive instrumentation of the NZERTF will provide high-resolution data collection and analysis methods to be used for comparisons of equipment performance based upon design intent versus actual realized equipment performance. In situ performance measurements may also provide insights to improve current energy modeling tools.

The NZERTF will enable such experimentation and can include: the in situ performance of a building as an integrated system; building equipment and systems; distribution systems and the effects of ductwork; heat pump realized performance for space conditioning; domestic hot water production; and multiple alternatives for dehumidification. Future research on in situ performance may include the ground-source heat systems and energy storage technologies. Other relevant performance parameters in addition to in situ performance can also be examined, including indoor environmental quality and factors affecting occupant satisfaction and comfort.

\footnotetext{
${ }^{30}$ See for example, National Electrical Manufacturers Association (NEMA).
} 
Together, these broader performance measures can be used to refine performance-based codes and standards that can be applied to both residential and commercial buildings.

\section{Research and Development Opportunities - In Situ Performance}

- Develop Uniform Technical Standards to establish the true performance of installed equipment:

- Evaluate the level of agreement between in situ performance measurement with laboratory measurements and the effect of occupant use patterns or programmed mode of operation on overall realized performance.

- Leverage data analysis methods to enable resolution of design intent versus actual building performance.

- Assess partial load performance of equipment (e.g., HVAC) versus laboratoryrating load and testing conditions.

- Develop standard methods of reporting performance data from the field in reallife conditions and establish standard measurement requirements.

- Evaluate installed transient and steady state performance.

- Develop protocols to measure in situ equipment performance. This includes fault detection, actual or realized performance, and sustained performance over time (e.g., detection of system drift):

- Leverage first-year baselines of system performance in measurement of longerterm equipment performance and system drift.

- Quantify in situ performance and delivered heating/cooling in forced air systems: (see also Section 3.2.1 Central Air Distribution System)

- Assess the effects on the air/heating/cooling delivery relative to ductwork configurations and effective flow rates delivered.

- Establish the overall performance effect of distribution systems on central air systems.

- Develop procedures for rating the as-installed performance of water distribution systems:

○ Include effects of piping materials, low-flow fixtures, manifold systems, and the characterization of use patterns at every "end" water fixture.

- Compare measures of overall building/system performance to the aggregated performance of individual devices or components. Identify and characterize factors not previously known to affect aggregated performance measures.

- Investigate residential device interactions and their effects on overall performance:

$\circ$ Examine effects on secondary factors such as IAQ or zone temperature control effects.

- Quantify impact of heat pump runtimes on the overall HP performance for space conditioning and dehumidification: (See also Section 3.2.2 Air Source Heat Pump Systems):

- Evaluate the effects of varying latent loads on HP dehumidification performance

- Identify and quantify internally generated latent loads and their relative effect on overall HP performance within specific climate zones. 
- Compare central HP dehumidification to dedicated stand-alone whole-house dehumidifiers with respect to energy efficiency and system performance.

- Evaluate heat pump performance based on its mode of operation - infrequent, shared or dedicated mode, full or partial capacity operation, high/low speed, varying signals from zoned thermostats (resulting in resistance-based heat generation), and grid pricing information.

- Perform continuous comparative analysis of measured vs. expected performance of HVAC and refrigeration equipment:

○ Include distribution systems in the analysis and testing procedures.

- Measure the energy use of DC-powered appliances, plug loads and end-uses; calculate effective energy use including power inverter losses for renewable DC energy sources.

- Evaluate energy storage technologies/materials, identify technologies that are effective, and acquire data on the in situ performance of these technologies.

- Quantify in situ performance of intelligent/automated LED lighting systems including controllers, power conversion, and communication systems.

\subsection{Intelligent Residential Systems}

\subsection{Intelligent System Control}

While the number of commercially available control systems for the residential market is a fast growing market ${ }^{31}$, current residential product offerings lack key features such as privacy protections, interoperable communication schemes, and protocols for anonymously collecting and sharing residential performance and system data. Commercial building control systems in general are expensive to install and more complicated to operate, limiting their applicability in the residential market. Regardless, both residential and commercial control systems must address the compatibility of equipment and the use common information sharing protocols. Currently, high installed costs, conflicting commercial interests, and the lack of information protocols, interoperability standards, and interchangeability standards hamper the penetration of control systems into small commercial and residential markets.

Advances in instrumentation, test methods, standard protocols, and best practices from research can help improve the usability of residential control systems and enable development of intelligent system algorithms that are responsive to exterior sources (actual/forecasted weather conditions), internal sources (occupancy sensors, thermostats, IEQ preferences, illumination levels) and use intelligence rulemaking (e.g., learning behaviors and use patterns).

\section{Research and Development Opportunities - Intelligent System Control}

- Define characteristics and essential capabilities for small commercial or residential control systems:

\footnotetext{
31 “Samsung Buys Into Home Automation with SmartThings Acquisition”, Time Magazine, August 15, 2014. https://time.com/3117493/samsung-home-automation-smartthings/
} 
○ Quantify the lifecycle costs and potential energy performance benefits and penalties using residential building controls.

- Investigate intelligent control systems for residential appliances and systems:

○ Evaluate system controls for residential appliances and systems that require different (discrete vs. continuous) control strategies and their effects on optimal system operation.

- Investigate barriers (cost, privacy concerns, etc.) to broad scale adoption of building control systems in the residential setting.

- Test and evaluate advanced controls and optimization of equipment operation and the effects of mixed-use loads, and occupant sensors on overall performance.

- Evaluate feasibility of automated learning for intelligent control devices:

- Identify or evaluate adaptive strategies based upon automated learning of occupant behaviors and schedules, user-supplied constraints, and system operation and performance criteria.

- Identify privacy issues for collecting and sharing residential system data and use patterns in the residential setting. Evaluate the adequacy of protocols for (anonymous) sharing system and performance data.

- Examine the extent and effectiveness of currently available residential technologies in an intelligent system control strategy:

- Evaluate use and performance of programmable, setback, and internet-enabled thermostats for zoned temperature control and their effects on energy performance, thermal comfort, and IAQ.

- Evaluate use of exterior sensors, body/infrared sensors, and automated lighting controls used as components to an intelligent system control.

$\bigcirc$ Evaluate the energy penalty for controllers used in automated high-efficiency LED lighting systems including power conversion and communications.

- Investigate and document interoperability issues related to proprietary communications protocols, controllers, transformers used in automated lighting control.

- Investigate intelligent/on-demand control systems to achieve required ventilation requirements. (See also Section 3.2.6 Other Ventilation Systems.)

- Leverage existing technologies and data to achieve more effective automation/building control strategies for residential buildings.

\section{Research and Development Opportunities - Intelligent Systems/Appliances and the Smart Grid}

- Integrate intelligent control systems of appliances/systems for Smart Grid interactions:

- Develop/evaluate standards, protocols, and reference implementations for a Smart Grid interface.

- Develop dynamic control strategies (e.g., sell or store?) for energy generated by renewable energy sources interacting with Smart Grid pricing signals.

- Identify operation strategies for appliances/systems to leverage Smart Grid pricing signals. 
- Collaborate with the Association of Home Appliance Manufacturers and ENERGY STAR to model and simulate use cases for the demand response and spinning reserve requirements for appliances.

- Develop a common definition on required capabilities for smart appliances.

- Introduce use of new "smart"/connected appliances to begin testing Smart Grid capabilities:

- Create demonstrations/reference implementations of communication protocols and test approaches for current market offerings.

- Evaluate commercial applications ${ }^{32}$ for controlling residential systems for:

- Adequacy of the standardized data and communication protocols.

- Privacy and security protections.

- Display of building control system and smart meter/smart grid performance information appropriate and useful to the typical homeowner.

- Develop an energy management system that optimizes whole-building/system operation with the Smart Grid:

- Evaluate experimental agent-based control systems to provide discrete controls driven by equipment data, individual settings, occupant preferences, transactionbased grid information, and demand/response information.

- Characterize performance for recognized and unanticipated events.

- Develop standard test protocols and metrics for interoperability.

- Investigate intelligent energy management systems that enable more efficient operation of grid-aware and standard appliances using pricing and environmental information (Facility Smart Grid Information Model ${ }^{33}$ ).

- Develop strategies for leveraging utility pricing signals and demand response for residential applications that involve EV energy storage and/or grid-aware HVAC systems.

- Determine limitations of current residential network and digital network router technologies to implementing appliance communications and grid response strategies:

- Evaluate performance and capacity of WiFi and low-power mesh networks.

\subsection{Fault Detection and Diagnosis}

With today's offerings, limited fault detection and diagnostic (FDD) capabilities for residential appliances are available - more often home appliances provide a single error code on local display screens that requires a trained technician to interpret and resolve. Improved FDD technologies and corresponding empirical appliance data on fault frequency can significantly impact energy use for buildings - heat pump and air conditioning equipment performance in commercial buildings can be easily degraded by as much as 20 percent due to faults or errors

\footnotetext{
${ }^{32}$ Ibid.

${ }^{33}$ BSR/ASHRAE/NEMA Standard 201P. http://spc201.ashraepcs.org/
} 
made in installation and maintenance ${ }^{34,35}$. Improved fault detection and diagnostic schemes developed and tested in the NZERTF can be used to measure and map the performance of systems over time and enable new strategies to correct their operation when performance parameters leave their expected range (commonly referred to as system drift).

\section{Research and Development Opportunities - Fault Detection and Diagnosis}

- Use NZERTF as a test bed in the development of methods of test in the evaluation of controls and FDD technologies.

- Improve fault detection and diagnosis technology for residential appliances and systems:

$\circ$ Detect and communicate system drift from desired performance.

$\circ$ Extend FDD technology to include ventilation systems and system performance degradation.

- Determine feasibility of FDD procedures for return air ducts as the major source of leakage and for induced IAQ pollutants.

- Develop automated FDD approaches that extend usability to the residential setting and the typical homeowner.

- Develop FDD techniques for residential commissioning-related activities. (See also Section 6.3 Residential System Commissioning and Best Practices below.)

- Measure and quantify effects of FDD system faults from individual devices and their effects on overall system/building performance.

- Validate existing FDD laboratory testing suites/apparatus and FDD factors in residential energy models.

- Develop accurate and inexpensive FDD schemes that measure and map the performance of residential systems with respect to metrics such as temperature, pressure, humidity, flow rate, and power.

- Leverage high-definition simulations to characterize fault events and validate FDD approaches and results.

- Generate high-definition operational data to characterize FDD situations for model and tool developers.

- Develop analysis tools/models for fault detection.

- Evaluate the ASHRAE Method of Test for FDD Algorithms:

- Evaluate prototype algorithms of heat pump performance and fault detection for low refrigerant levels, and clogged filters and heat exchangers.

\footnotetext{
${ }^{34}$ Mowris, R.J., Blankenship, A., Jones, E., Field Measurements of Air Conditioners with and without TXVs. ACEEE 2004 Summer Study on Energy Efficiency in Buildings, American Council for an Energy Efficient Economy, Washington, DC, 2004. http://www.aceee.org/

${ }^{35}$ Neme, C., Proctor, J., Nadel, S., Energy Savings Potential from Addressing Residential Air Conditioners and Heat Pump Installation Problems. Report Number A992, American Council for an Energy Efficient Economy, Washington, DC, 1999. http://www.aceee.org
} 


\subsection{Residential System Commissioning and Best Practices}

Commissioning ( $\mathrm{Cx}$ ) of equipment (components, subsystems, and systems) in today's residential buildings is rare and generally cost prohibitive for the typical homeowner. As a result, formal residential commissioning practices are not well established and local residential building codes traditionally focus on life-safety issues.

Increased automation and improved residential commissioning procedures and guidelines can lead to improved performance (productivity, energy, and comfort), lower labor costs, and lead to "continuous" or ongoing system commissioning and its associated benefits. Tools that automate single or multiple phases of $\mathrm{Cx}$ (design, construction, performance, testing, correction, documentation), as well as tools specific to building systems (e.g., lighting, HVAC, water) are needed.

\section{Research and Development Opportunities - System Commissioning}

- Investigate R\&D opportunities for commissioning and continuous commissioning for residential building systems.

- Identify operational procedures and data required for residential system commissioning.

- Leverage high-resolution building simulations to identify residential systems/equipment with the largest impact on improved performance and required maintenance:

- Identify critical parameters for building design, the accuracy needed, and ways to measure the in situ performance and operation (e.g., FDD) of these systems.

- Identify and quantify commissioning-related systems and data that can effectively address IAQ concerns and issues.

- Identify and validate best practices and guidance for new construction requiring improved design details and assembly practices that will improve new construction outcomes (e.g., 2012 BSC Residential Best Practices Criteria).

- Evaluate rating systems (e.g., HERS, LEED, Energy Star) used for highperformance residential building applications. Determine more sophisticated metrics for rating IEQ.

- Quantify critical factors that can be used to update/improve current rating systems and to address training and certification requirements.

- Identify key systems and features/issues that affect the acceptance of NZE residential buildings by consumers and real estate/developer stakeholder groups, improve occupant satisfaction, and support the economic business case.

- Develop methods of measurement for quality control of construction - e.g., imbedded sensors in construction materials for quantitative measures of in situ performance.

\subsection{Data Collection and Modeling}

Collection, management, and interpretation of building data present numerous challenges. Information models and standards that effectively capture the measurement and issues related to intelligent control are lacking. Ancillary to this technology gap is the need to identify and collect 
building data/information to "spotlight" or identify poor performing buildings or building systems.

\section{Research and Development Opportunities - Data Collection and Modeling}

- Expand the use and development of data models for Data Sharing and Protocols and Data Collection and Interpretation:

- Develop/evaluate standard data formats that enable easy sharing and retention of data: e.g., design data useful in evaluating operations, or to make modifications for changes in building usage.

- Develop/evaluate approaches for Building Information Models:

- Data protocols for all facets of data collection;

- Standard formats for transferring data from systems to analysis tools.

- Develop/extend a uniform data specification for the NZERTF that can be leveraged by the broader community (see also EPA/DOE high-resolution Building Performance Database $\left.{ }^{36}\right)$ :

- Develop standardized data model and analytic tools;

- Develop framework and ontology for collecting information in a uniform data repository with verified analytic tools;

- Disseminate information to academia and industry.

- Produce a standard functional Integration Definition (IDEF):

- Develop proof of concept for the formalized description of data and a method of test used to establish Standard Functional Performance Tests.

- Demonstrate the IDEF for commissioning use.

- Use the IDEF to properly characterize how performance changes over time.

- Leverage high-definition data collection in the NZERTF test environment:

O Identify the minimal data and data-collection frequencies needed for a NZE single-family residence.

$\circ$ Use high-definition operational data at the switch/equipment level for model/tool/dashboard development, testing, and validation.

○ Compare in situ system performance results with results derived from Energy Plus, TRNSYS, and other energy simulation models:

- Identify building equipment/systems that have large uncertainties in their modeled performance.

- Examine seasonal data on energy performance to validate current approaches in modeling seasonal energy consumption.

- Characterize individual load with higher accuracy to improve the whole building performance modeling.

- Identify and quantify hidden or unforeseen passive loads in residential models.

- Expand and improve the quality of data used in simulation models (vs. real-world data) to aid in validating and creating better predictive performance models:

- Extend simulation models validated against the NZERTF data to other climatic zones.

\footnotetext{
36 The Buildings Performance Database (BPD), U.S. Department of Energy, Washington DC. http://energy.gov/eere/buildings/buildings-performance-database.
} 
- Evaluate and calibrate residential energy models and analysis tools.

- Develop models that integrate energy analyses for the whole buildings, including enduses:

- Evaluate impacts of use patterns and occupant behaviors on overall performance and energy-use predictions.

○ Model energy use of DC-powered appliances, plug loads and end-uses; quantify associated power conversion losses from renewable DC energy sources.

○ Develop "short-term" energy use models for specific load types (for application with the grid-aware and Smart Grid technologies).

O Optimize equipment performance for net-zero energy buildings.

- Develop data requirements and analysis for assessing building performance including:

○ Identifying the critical parameters for building design, the required accuracy in quantifying these parameters, and strategies to measure these parameters in existing buildings.

- Gathering a minimal set of data to assess building energy consumption (to within a known accuracy).

- Develop a clear definition of how data will be used.

- Metrics used to measure performance (versus models that use those measures).

- Required accuracy of sensors to measure inaccurate mechanical systems (e.g., malfunctioning air dampers and actuators).

- Evaluate available data acquisition and dissemination standards and protocols for sharing residential energy and building control data in comparisons, energy modeling, and smart grid interactions.

- Develop test procedures/methods and net-zero performance evaluation standards to address realized operational performance in a NZEB.

- Collect and make publicly available experimentally derived data on NZEBs for evaluating and calibrating models, performing gap analysis, estimating performance targets, and validating assumptions.

- Extend baseline data collection to include exterior environmental/seasonal variations and other environmental parameters.

\subsection{On-Site Water Collection and Water Reuse Systems}

Water conservation and recycling represent another potential research avenue for the NZERTF. Potable water systems previously described in Section 3.4 Water Fixtures and Appliances describe the water fixtures and appliances used in the facility and selected to conserve potable water. Water collection and water reuse systems can also be tested in the NZERTF. In a research setting, water collection and treatment technologies can be evaluated along with quantification of the avoided potable water consumption for non-potable applications such as toilets and landscape irrigation. State and local codes determine the legal applicability of reusing water or treating non-potable water for secondary purposes. 
"Greywater", including water collected from showers, clothes washers, and sinks when properly treated, can also be used for non-potable applications, contingent upon the local health codes. Reuse of "blackwater" or effluent from toilets is generally not allowed by local health codes though a small number of municipalities ${ }^{37}$ suffering from severe drought conditions have begun reusing water produced from treated effluent for potable water purposes. Research on the effectiveness or costs associated with the treatment of greywater or blackwater cannot be realistically performed in the NZERTF under the current scenario of a "simulated" family of four, as there is no (or minimal) human, kitchen, or laundry wastewater generated.

Water collection and reuse systems can be evaluated on their lifecycle cost for producing water for non-potable applications that include toilets and landscape irrigation. Water production levels for the collection and treatment systems can vary depending upon the time of year, application, settings, and design/control features used.

Other research topics could examine Low Impact Design (LID), a recognized approach to designing features into the building site to manage stormwater and reuse water where possible. LID employs principles such as preserving and recreating natural landscape features, minimizing effective imperviousness to create functional and appealing site drainage that treat stormwater as a resource rather than a waste product where collected rainwater provide new sources of usable water.

\section{Research and Development Opportunities - Water Appliances}

- Examine efficient and sustainable water appliances and strategies.

- Evaluate performance of new experimental water efficient technologies:

○ Composting toilets;

- Shower water recycling technologies (e.g., small capacity water systems using filtration and reheating units).

- Investigate water quality, pipe/fixture material effects, and bacteria or other contamination sources.

\section{Research and Development Opportunities - On-Site Water Collection Systems}

- Examine water quality before and after treatment for the presence of air-borne pollutants, acid rain. Estimate actual cost of production (including filtration/treatment and system maintenance) and potential reductions in potable water use.

- Evaluate site water collection and treatment capabilities for secondary water reuse purposes (e.g., irrigation, toilet operation, fire suppression technologies).

- Evaluate state and local codes and develop guidance and test data used to define the legal applicability of water reuse or treating rainwater/grey water for non-potable purposes.

${ }^{37}$ E.g., Wichita Falls, TX. http://tx-wichitafalls2.civicplus.com/index.aspx?nid=1595 
- Develop standards and methods of test for water reuse based upon the full range of environmental factors (climate zone, collection materials, water uses, airborne contaminant levels):

○ Investigate water collection systems and use of storm water for secondary nonpotable water applications including toilets, clothes washing, landscaping:

- Demonstrate and document the performance and reliability of residential water treatment systems for recycled/collected water sources for use in secondary non-potable water applications.

- Evaluate the reductions in potable water using greywater for health-code approved applications.

- Develop economic measures for water reuse technologies that may provide safer, cleaner, and cheaper (in terms of actual delivered costs) water than is provided by water utilities to the residence.

- Acquire test data to assess and document actual performance of reuse technologies.

- Evaluate performance of water treatment technologies that allow greywater (or effluent) to be treated and returned as a potable water supply. Demonstrations and related performance data are needed to advance new water supply technologies.

○ Design and evaluate Low Impact Design landscapes for water collection.

\subsection{Other}

The NZERTF may be useful in better understanding "behavioral" impacts driven by more efficient/NZ building operation.

Coordinate with the National Institute of Building Sciences (NIBS) and DOE in creating "better" definitions and terminology for NZ buildings as well as appropriate metrics. Identify the most relevant metrics for $\mathrm{NZ}$ performance characterization.

Characterize the GHG impacts regionally for a NZEB based upon consumer preferences for combustible fuel (e.g., NG) HVAC and standard appliances.

Identify residential technologies appropriate for small commercial building applications.

\section{Acknowledgements}

This work represents a compilation of the ideas and visions of a large number of individuals dedicated to improving the performance of residential homes and commercial buildings. The R\&D opportunities identified in this report were based upon conversations and material provided by a large number of contributors from a range of organizations: federal, private sector, academic, and nonprofit/professional associations. Research and development topics from the 2010 NIST Technical Note 1660 "Measurement Science Roadmap for Net-Zero Energy Buildings" provided the discussion material for the interviews and relevant R\&D topics from that report are replicated in this document. The full list of the contributing organizations is listed in Appendix A and reference reports in Appendix B. 
Descriptive text for many of the technical sections was taken from three technical reports describing the NIST Net-Zero Residential Test Facility. Betsy Pettit and Cathy Gates from the Building Science Corporation authored the NIST Technical Note titled "Design Challenges of the NIST Net Zero Energy Residential Test Facility". The second, titled "Net-Zero and Beyond! Design and Performance of NIST's Net-Zero Energy Residential Test Facility", is authored by A. Hunter Fanney, Vance Payne, Tania Ullah, Lisa Ng, Matthew Boyd, Farhad Omar, Mark Davis, Harrison Skye, Brian Dougherty, Brian Polidoro, William Healy, Joshua Kneifel, and Betsy Pettit. The third document is entitled "Monitoring Techniques for the Net-Zero Energy Residential Test Facility" and is authored by Mark Davis, William Healy, Matthew Boyd, Lisa $\mathrm{Ng}$, Vance Payne, and Harrison Skye, Taken together with this document, these reports provide a comprehensive overview of the NZERTF and its potential for research and development activities. 


\subsection{Appendix A: Contributing Organizations}

Air Conditioning Contractors of America (ACCA)

Air-Conditioning, Heating, and Refrigeration Institute (AHRI)

American Council for an Energy-Efficient Economy (ACEEE)

Auburn University (AU)

Bentley

Bosch North America

Building Sciences Corporation (BSC)

California Energy Commission (CEC)

Florida Solar Energy Center (FSEC)

Geothermal Exchange Organization (GEO)

Johnson Controls, Inc. (JCI)

Louisiana State University (LSU) - LaHouse

National Institute of Building Sciences (NIBS)

National Institute of Standards and Technologies (NIST)/Engineering Laboratory (EL)

New Buildings Institute (NBI)

U.S. Environmental Protection Agency (EPA)

U.S. Department of Energy (DOE)/Building America Program

U.S. Department of Energy/Oak Ridge National Laboratory (ORNL)

U.S. Department of Energy/National Renewable Energy Laboratory (NREL)

U.S. Department of Energy/Pacific Northwest National Laboratory (PNNL) - Lab Homes

University of California (UC), Davis - Honda Smart House

University of Texas (UT), Austin - UTest House

\subsection{Appendix B: Key Reference Reports}

Measurement Science Roadmap for Net-Zero Energy Buildings Workshop Summary Report, NIST Technical Note 1660, March 2010

Building and Fire Research Laboratory

National Institute of Standards and Technology

Gaithersburg, MD 20899-8630

Authors:

Joan L. Pellegrino, Energetics Incorporated

A. Hunter Fanney, Chief, Building Environment Division

Steven T. Bushby, Leader, Mechanical Systems \& Controls Group

Piotr A. Domanski, Leader, HVAC \& R Equipment Performance Group

William M. Healy, Leader, Heat Transfer \& Alternative Energy Systems Group

Andrew K. Persily, Leader, Indoor Air Quality and Ventilation Group

Design Challenges of the NIST Net Zero Energy Residential Test Facility, NIST Technical Note, 2014.

Authors:

Betsy Petit, Building Science Corporation

Cathy Gates, Building Science Corporation 
A. Hunter Fanney, Senior Research Scientist, Energy and Environment Division William M. Healy, Leader, Heat Transfer \& Alternative Energy Systems Group

The National Institute of Standards and Technology's Net-Zero Energy Residential Test Facility, draft NIST Technical Note, 2014.

Authors:

A. Hunter Fanney, Chief, Energy and Environment Division

Vance Payne, Energy and Environment Division

Tania Ullah, Energy and Environment Division

Lisa $\mathrm{Ng}$, Energy and Environment Division

Matthew Boyd, Energy and Environment Division

Farhad Omar, Energy and Environment Division

Mark Davis, Energy and Environment Division

Harrison Skye, Energy and Environment Division

Brian Dougherty, Energy and Environment Division

Brian Polidoro, Energy and Environment Division

William M. Healy, Leader, Heat Transfer \& Alternative Energy Systems Group

Betsy Pettit, Building Science Corporation 


\subsection{Appendix C: Other Figures}

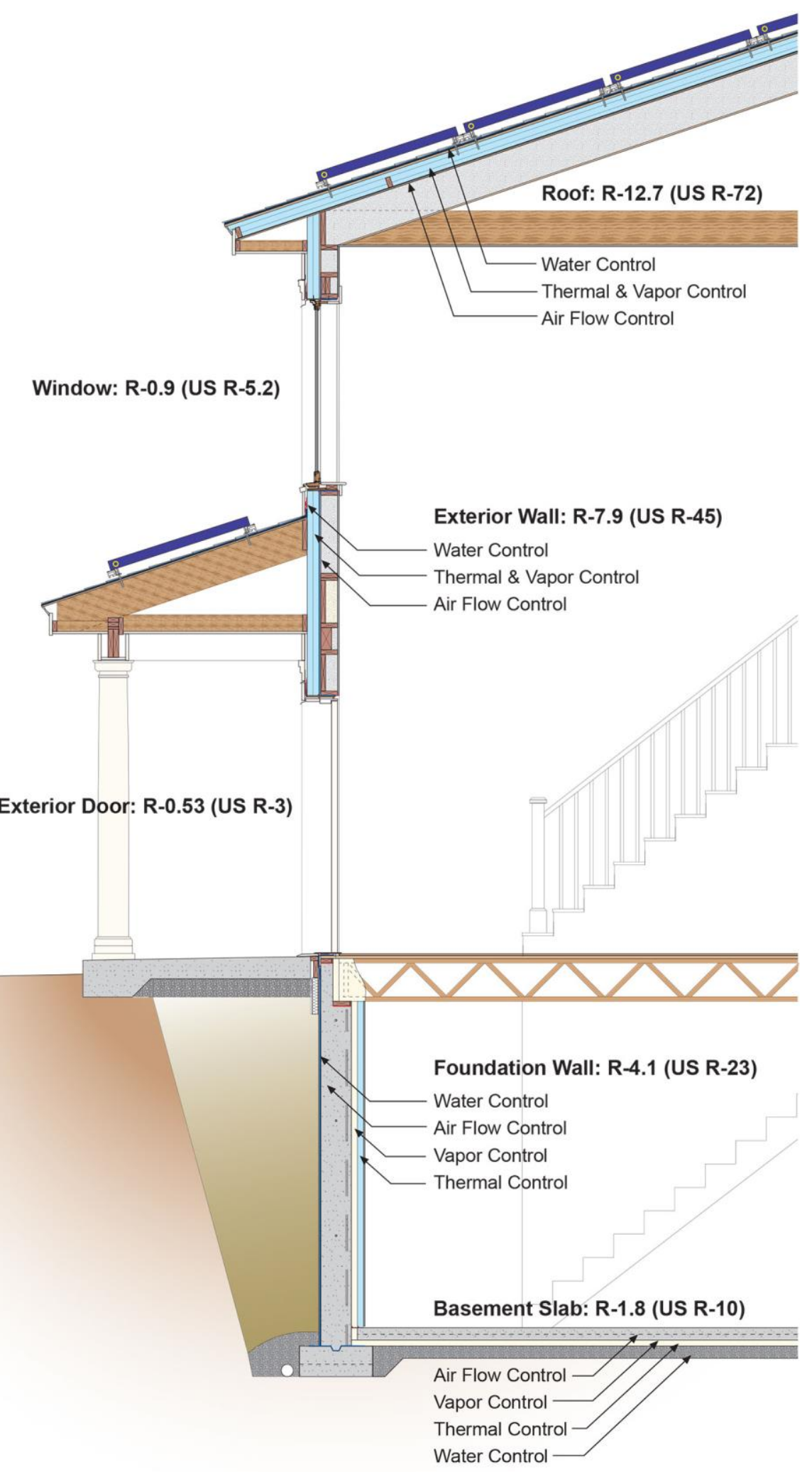

Figure 7: Building Enclosure Components with Nominal R-value 


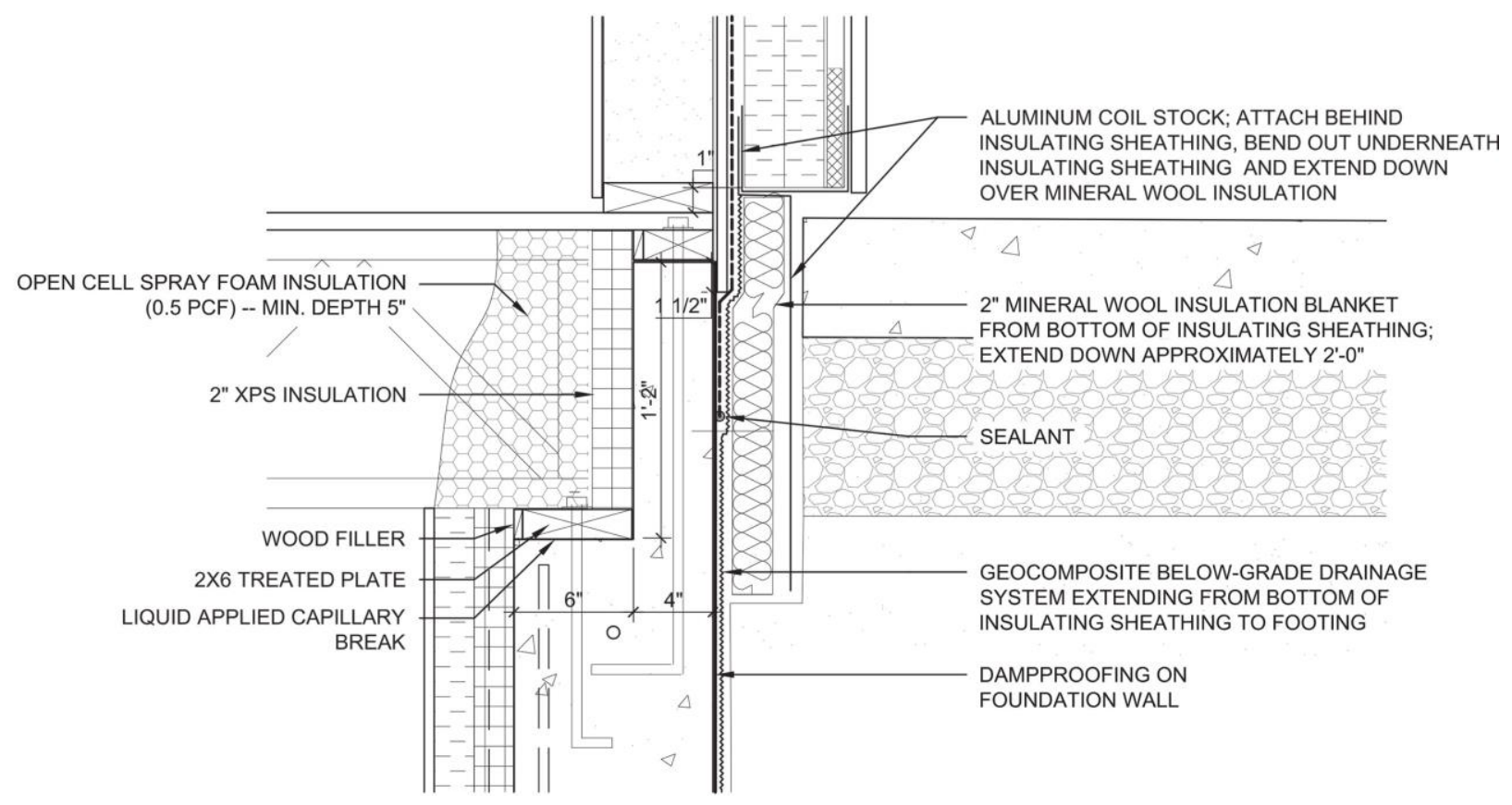

Figure 8: Top of Foundation Wall (from Construction Set) 


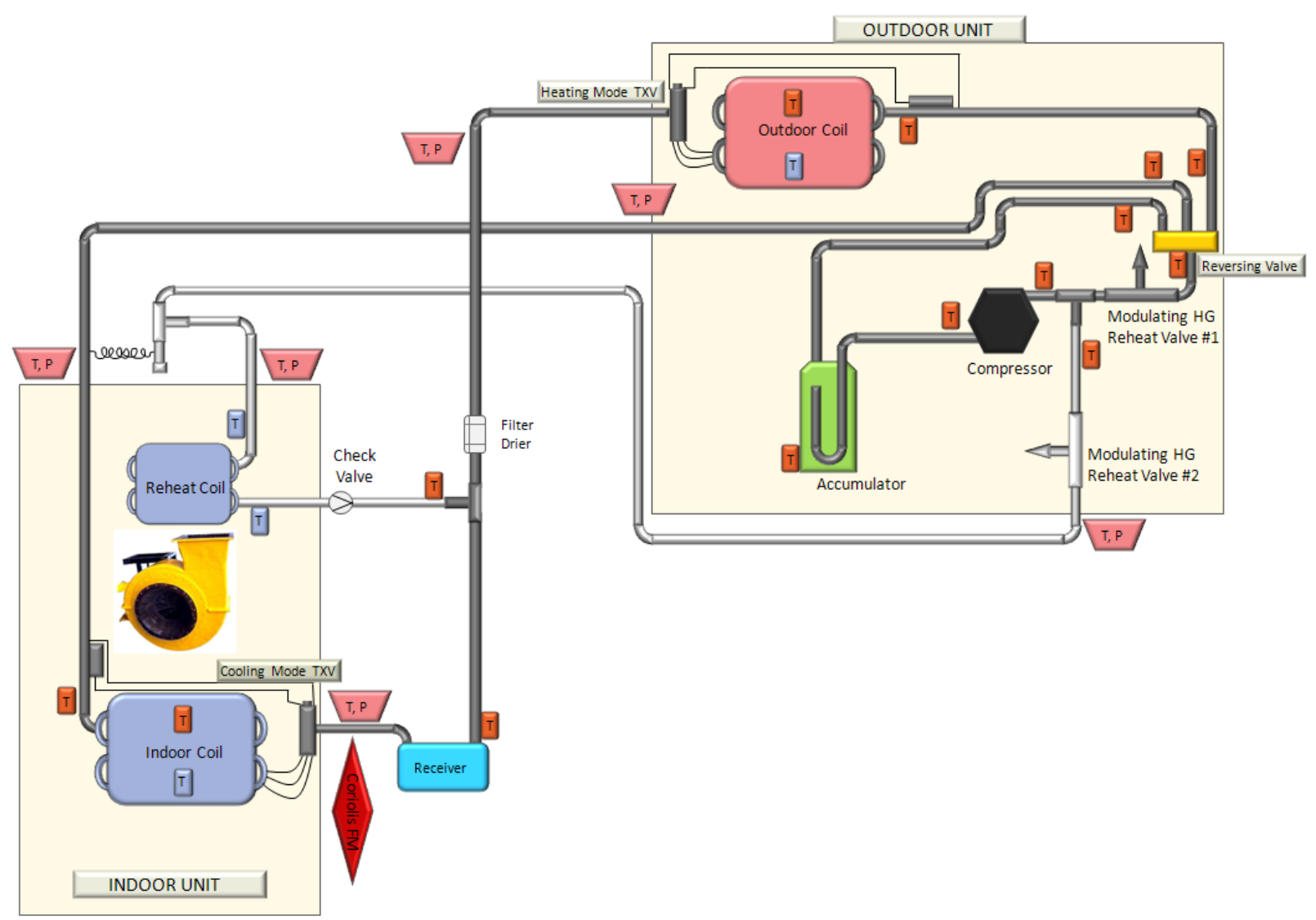

Figure 9: Heat Pump Refrigerant Circuiting and Instrumentation 


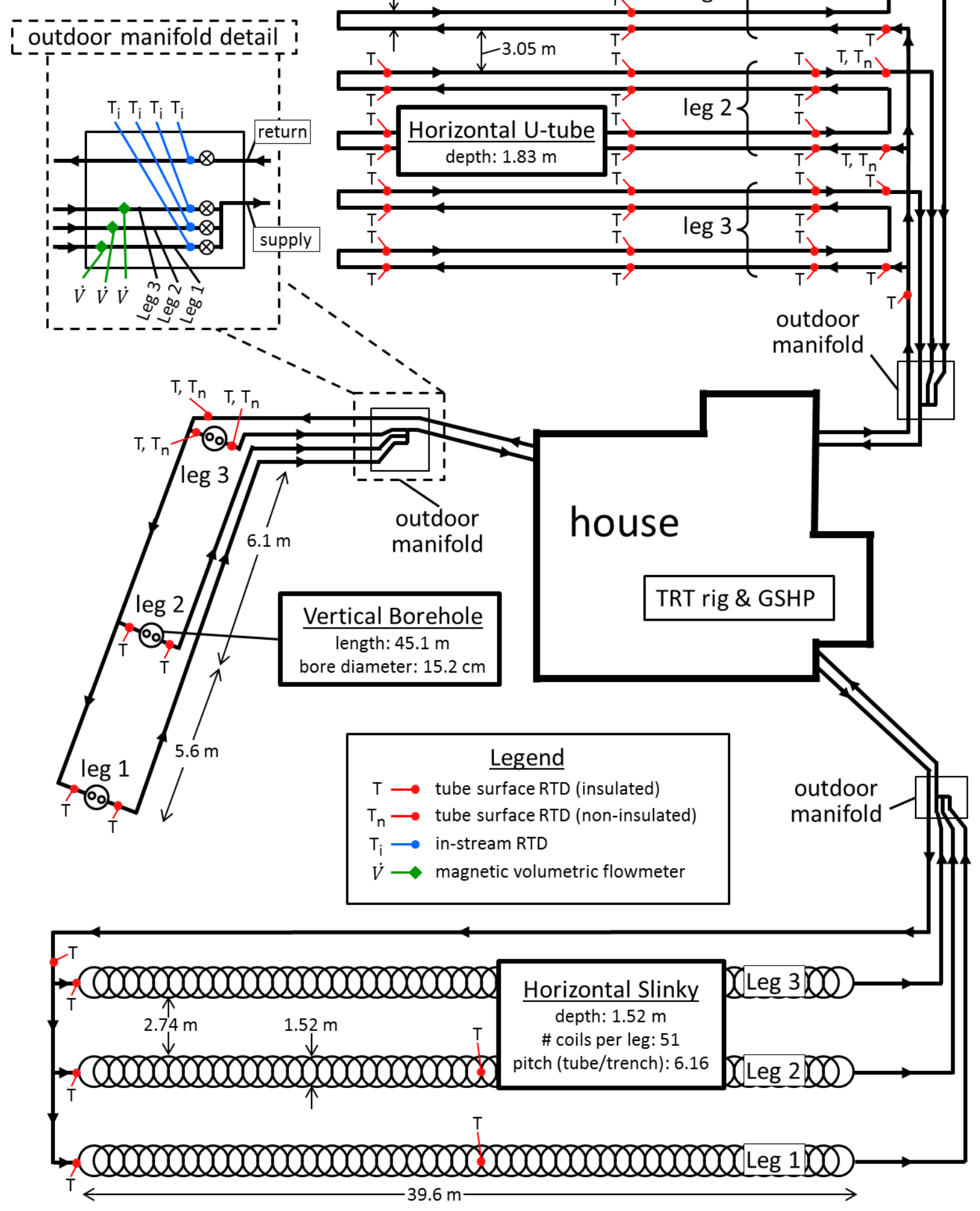

Figure 10: Ground Source Heat Exchanger and Instrumentation Schematic 